\title{
Questionnaire for Sensitive Positions (QSP) Version 4.0 - Users Guide Document
}

\author{
J.M. Hausel
}

West Inghouse Hanford Company/Boeing Computer Services Richland

P.0. Box 9970 , kichland, Un $\$ 5352$

H.S. Department of Enargy ConErack DE-ACOS-87R2,10930

\begin{tabular}{|c|c|c|}
\hline $\begin{array}{l}\text { EOT/ECh: } \\
\text { Org Codia; } \\
\text { ger Code: }\end{array}$ & $\begin{array}{l}615740 \\
62300 \\
\text { H3300000 }\end{array}$ & $\begin{array}{l}\text { tet: } \\
\text { Charge Codes: } \\
\text { Total Pages: }\end{array}$ \\
\hline
\end{tabular}

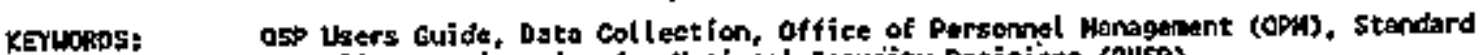
Form Bb, auestionali re for Hatlanal Stcurity Positions (QHSP)

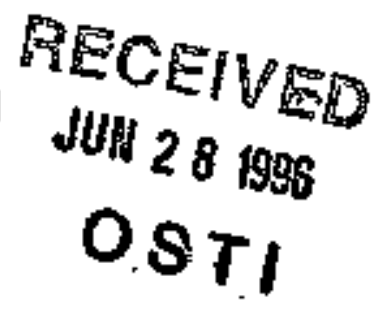

ABStRACT: The U.S. Government dose background fenestigations and coimwestigations to

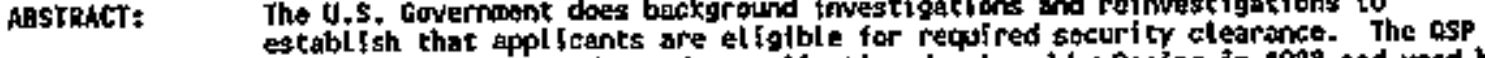
systect is an putonated Poridox application doveloped by eoeing in 1988 and used by oDE*RL for date collection, retentlon, and printing of facsimile of the standard Fara as containing a person's data nesded to conduct an imvestigation. In Harch

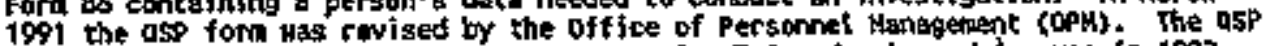
system was modiffed and enhaned to OSP version 3,0 and released for use in 1992. copies of osp version 3.0 were provitind to spproxitnetely 20 other sites when

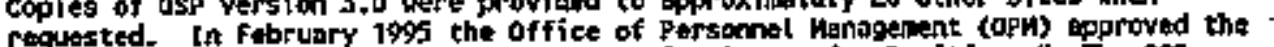

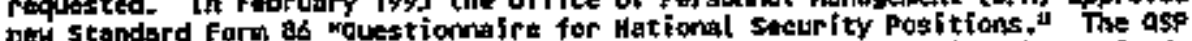
systo was eodified and upgraded to osp version 4.0 to agres with the rorlsed fom.

TRADEHARKS: Paradox is a trademark of Borhand Internationat, Ima.

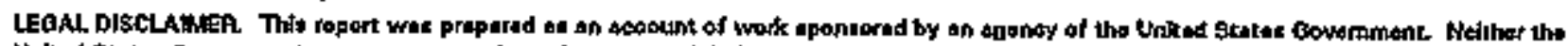

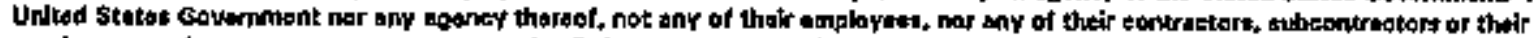

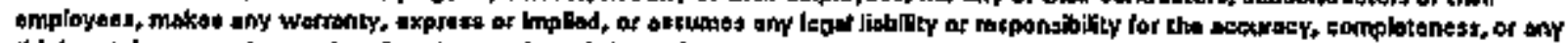

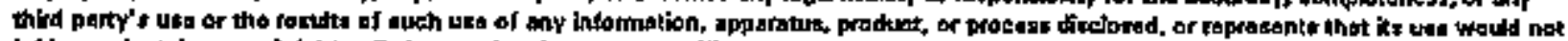

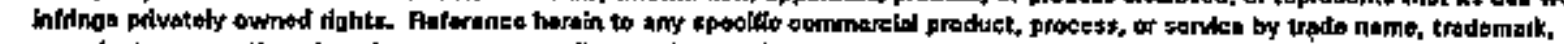

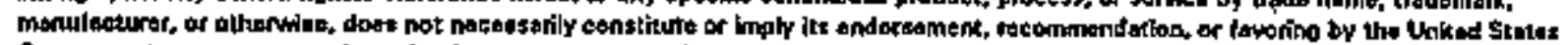

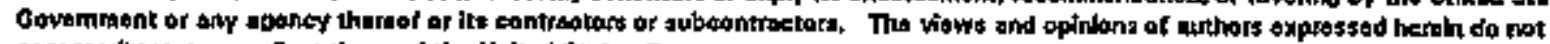
nasestefily tteste of raflact those of tha United States Govemment or ony agency thereof,

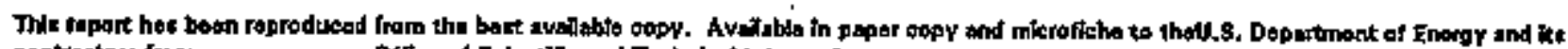
tapteractors Urom Oriteo of Belontirio and Tochnike information P.O. Bax 62, Oak Fitue. TN 37esi

Tolophono: 42s/670-0401

A wettoblo to the publle from U.S. Depertraent of Commanto

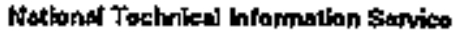

E285 Port flovet flowd, Springfiatd, VA 22361

. Tolephano: 703/487-4650

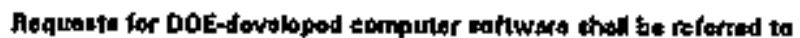

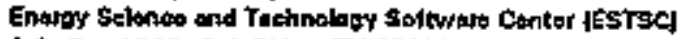
P.O. Box 1020, Oak Aidje. TN 37931

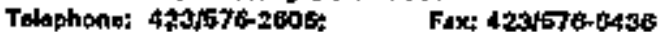
e-mall: acteces adonto.butlaov.
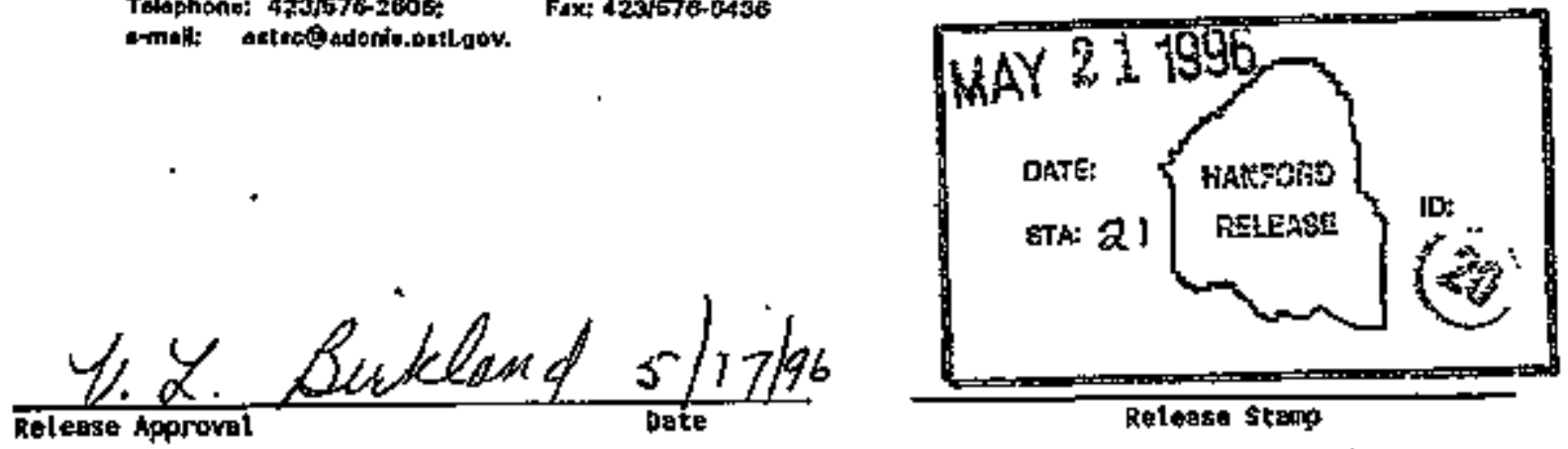

Reloese Strang 


\section{DISCLAIMER}

This reart wes prepaned as an wooknt of wort sposored by an agency of the Ulited

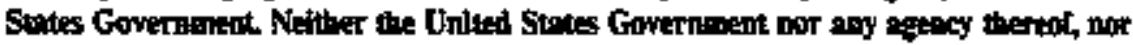

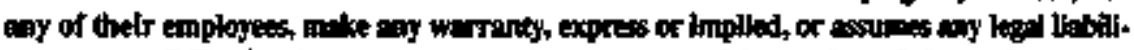

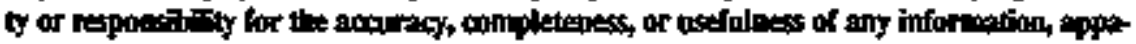

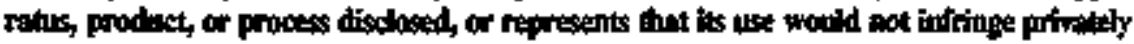

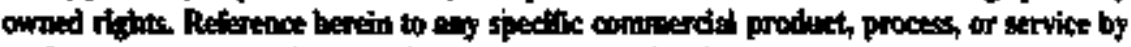

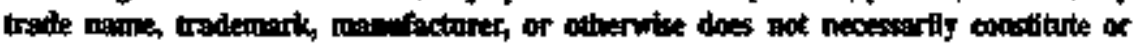

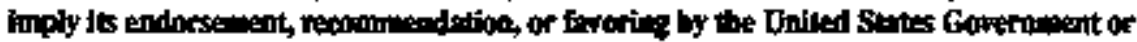

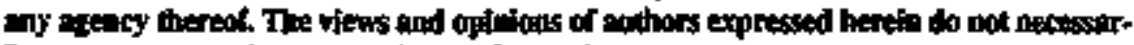
ily strie or relect thase of the United Strits Governmeat or any atency thereof. 


\section{DISCLA NMER}

Portions of this document may be fllegible in electronic image products. Images are produced from the best available original document. 


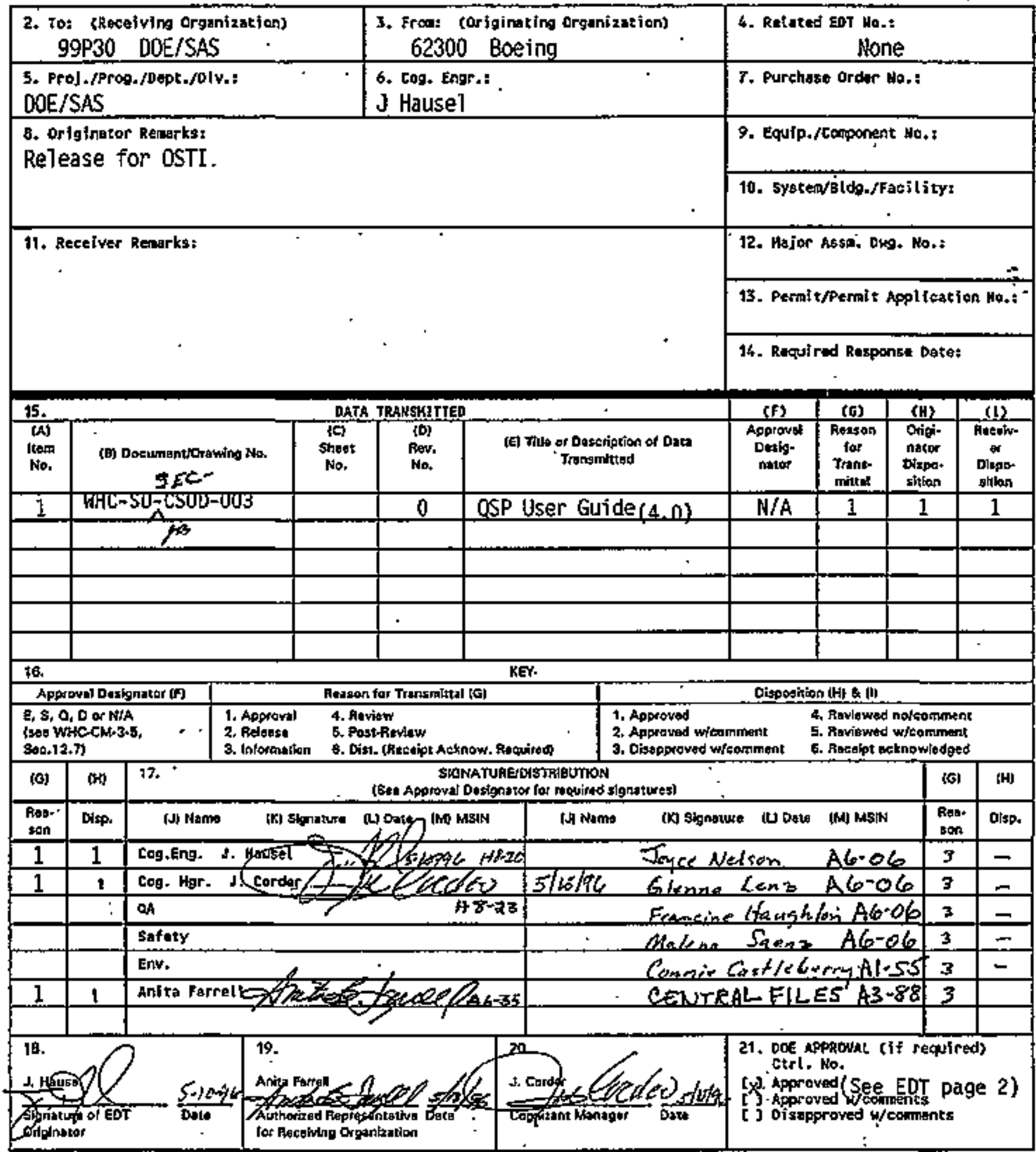


atlacknient ad $607+615740$

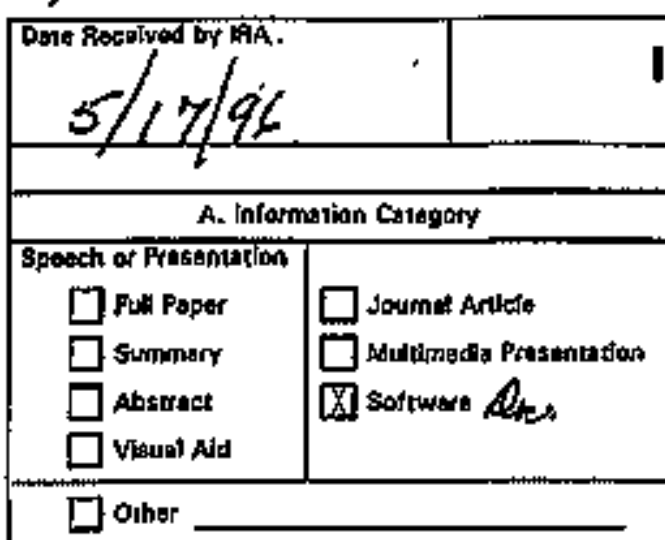

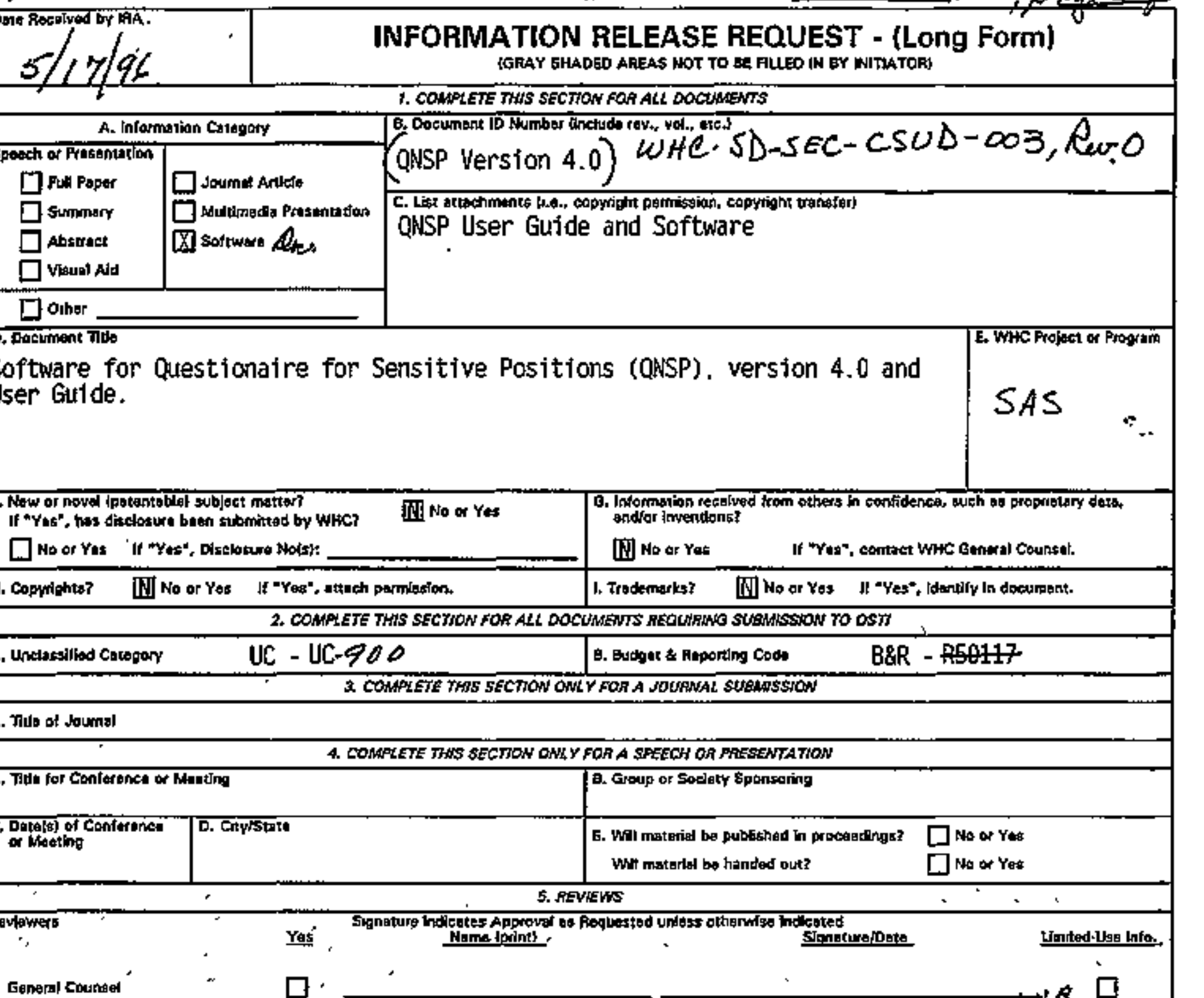

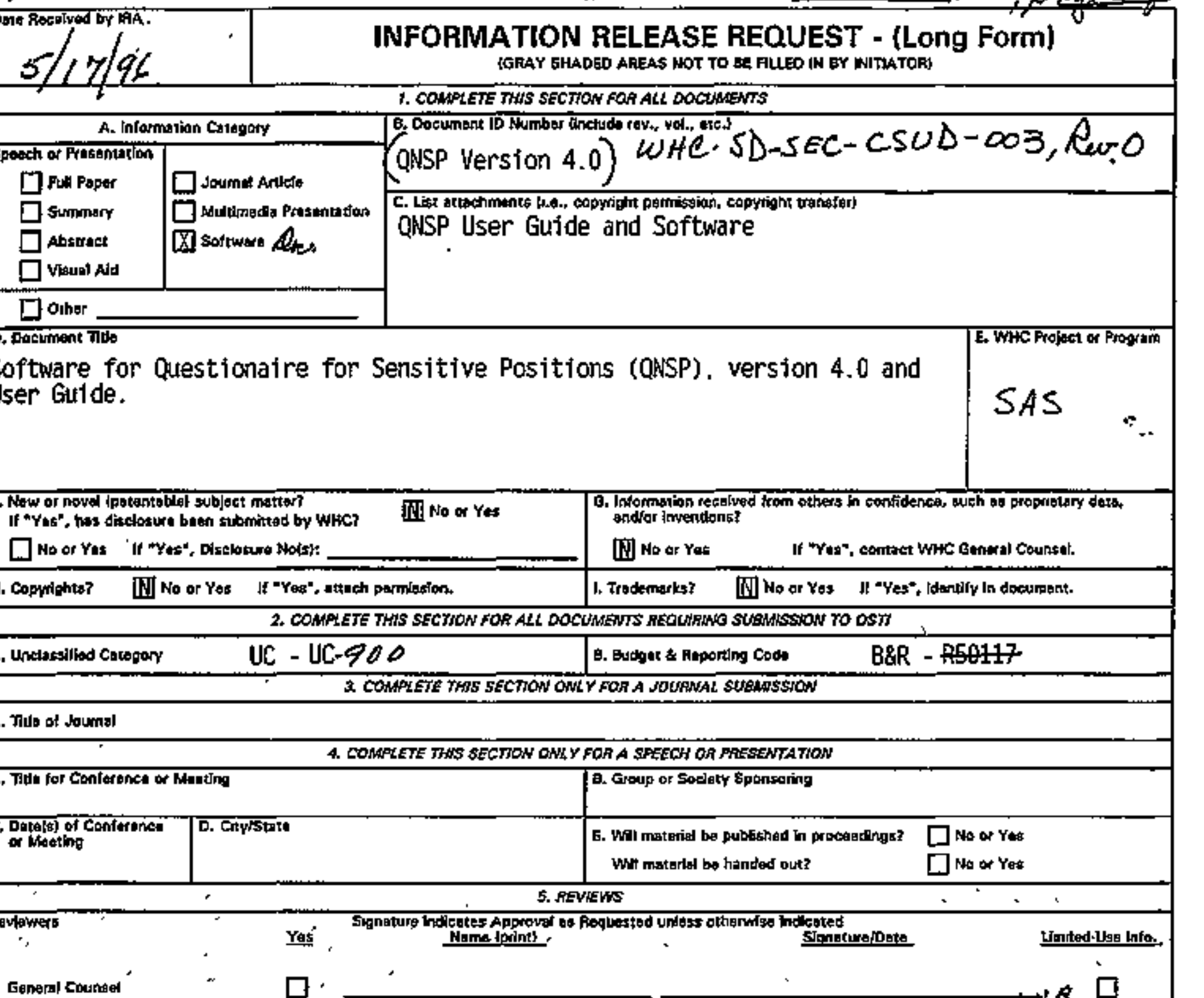

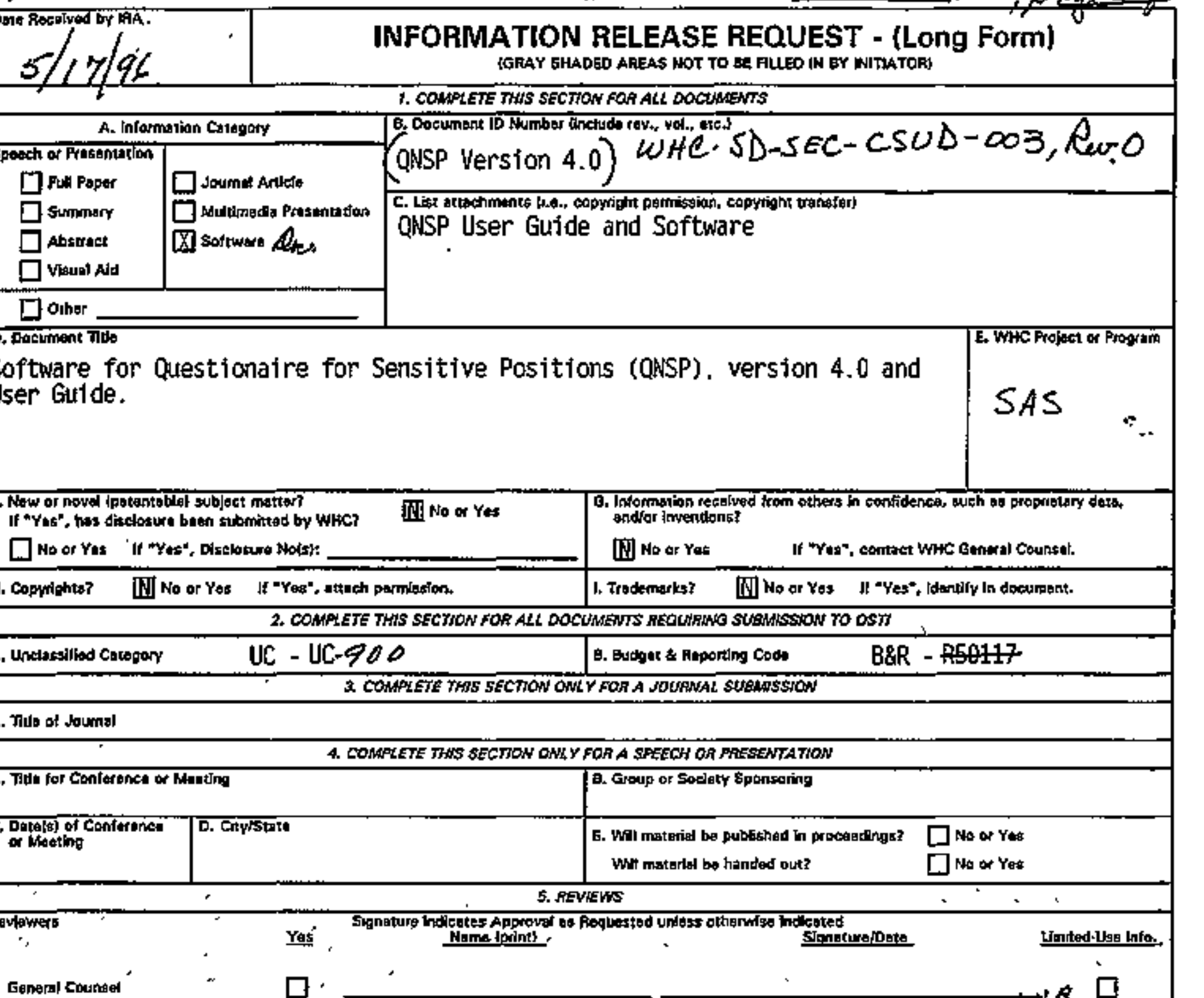

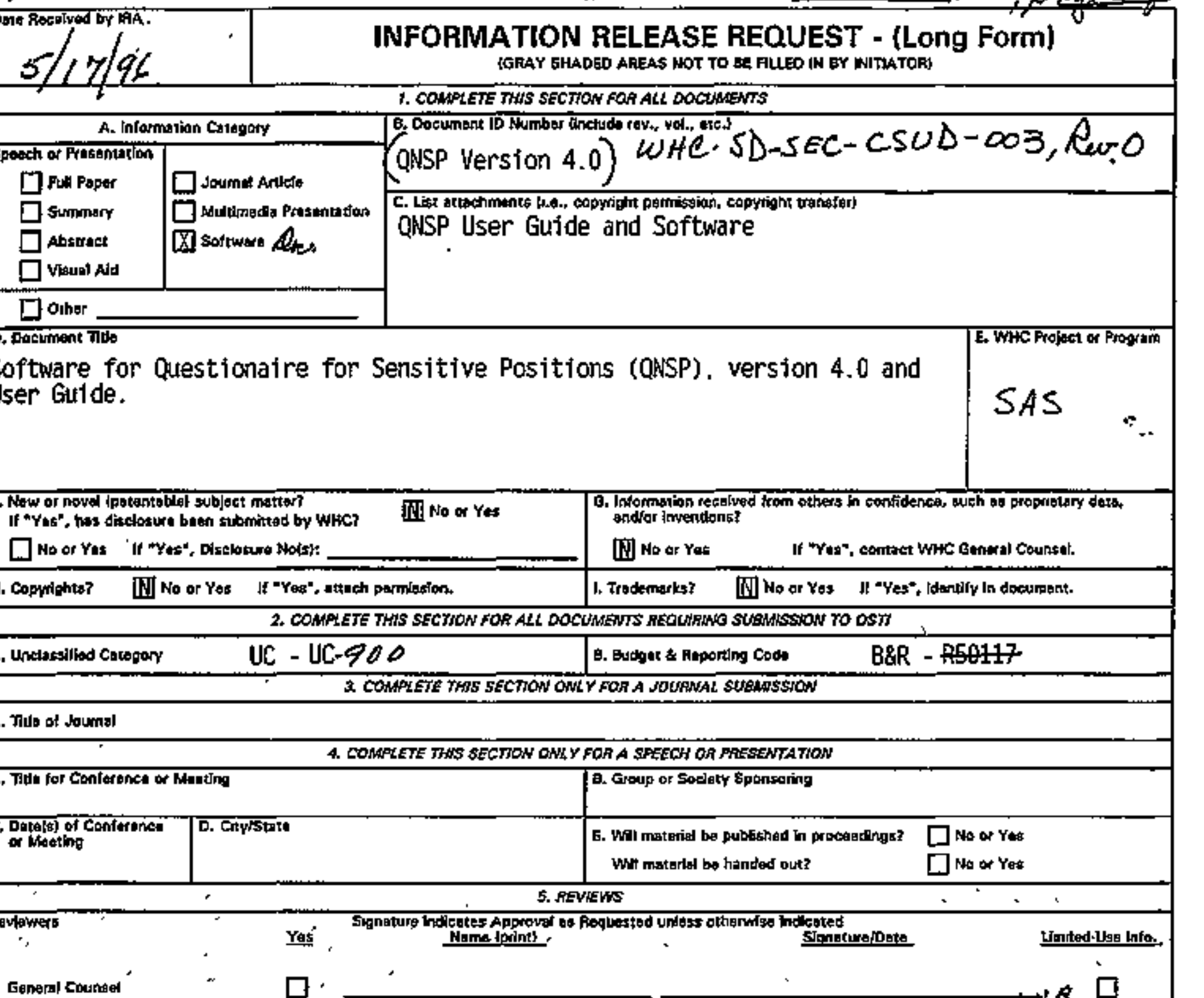

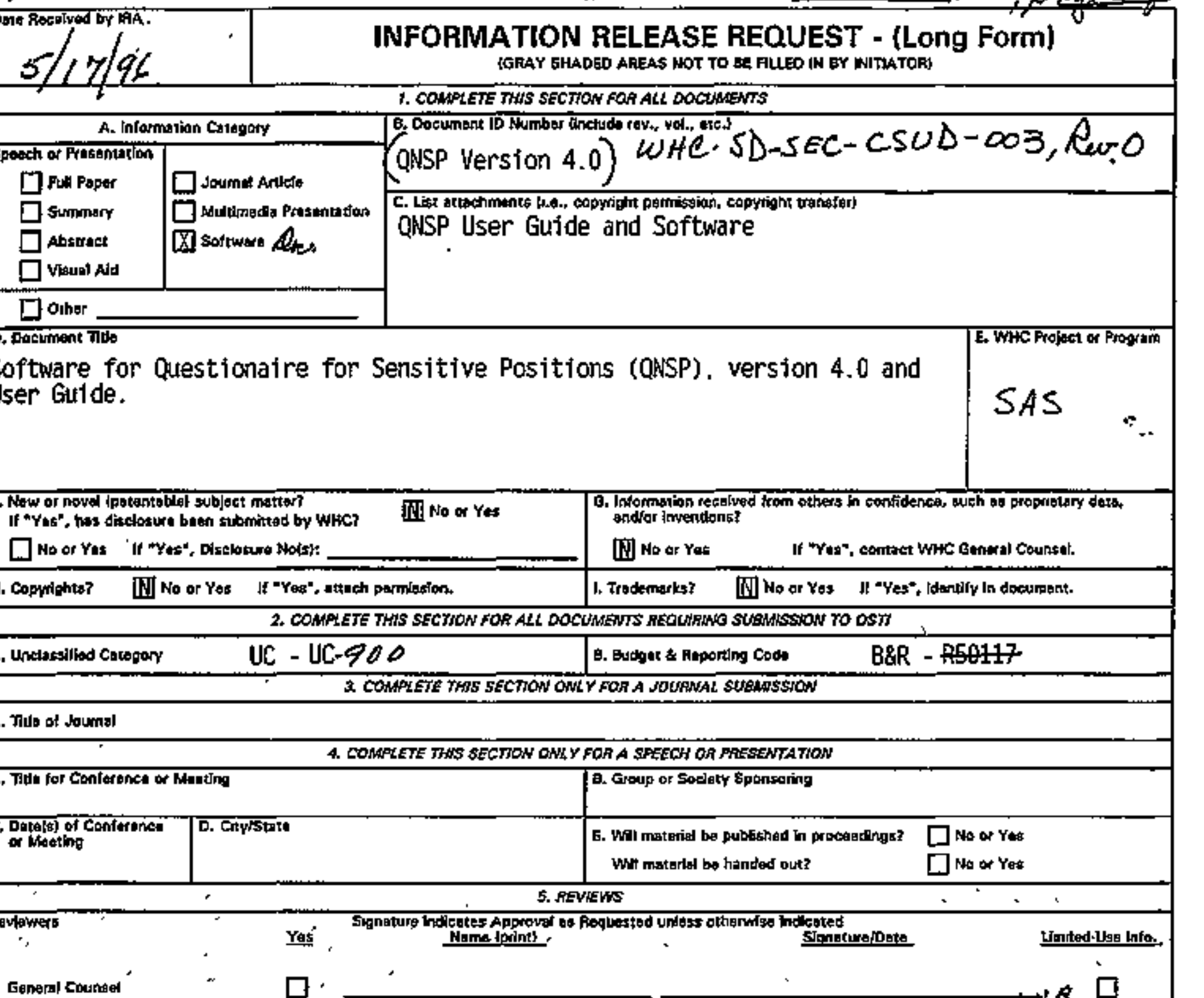

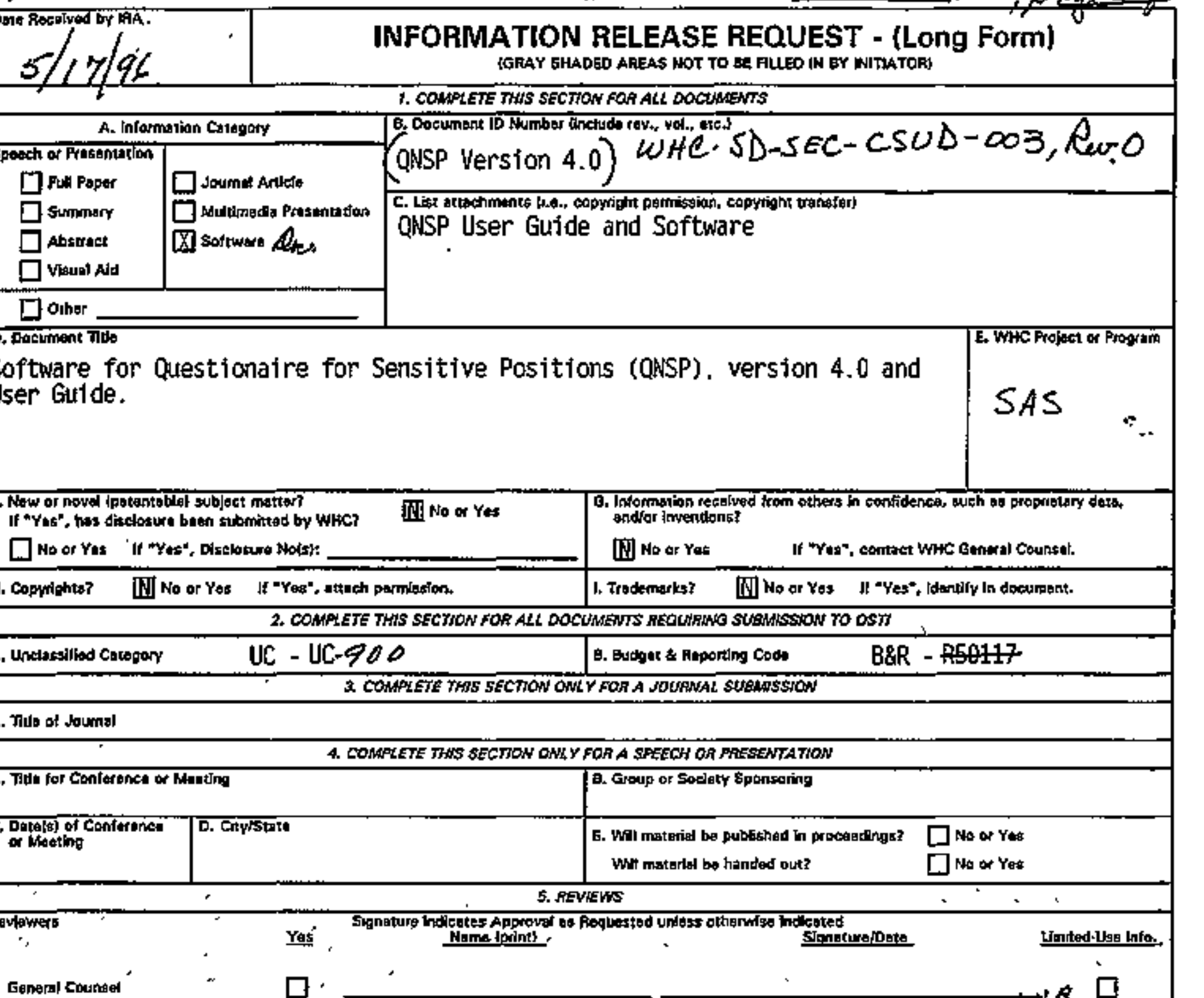

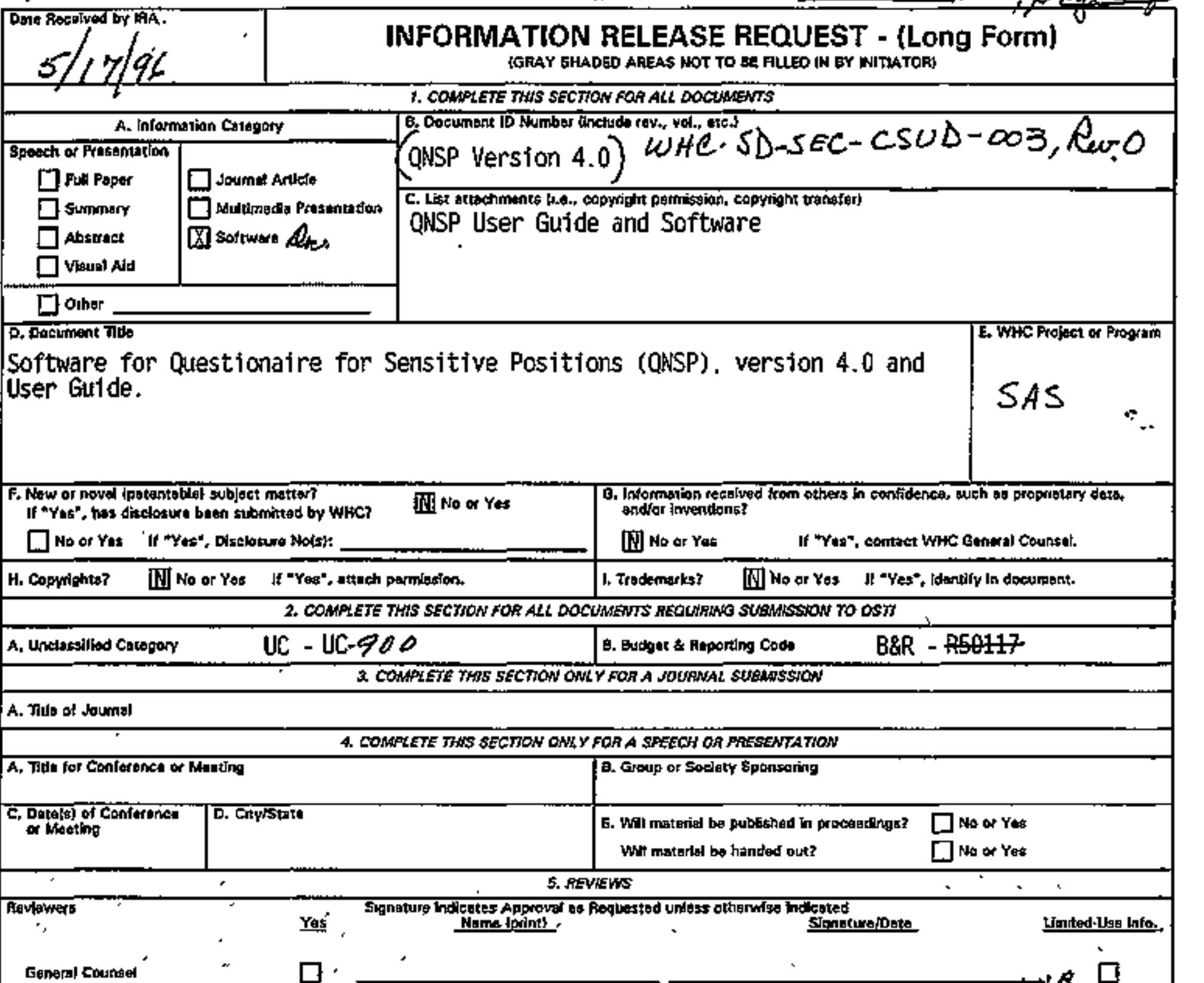

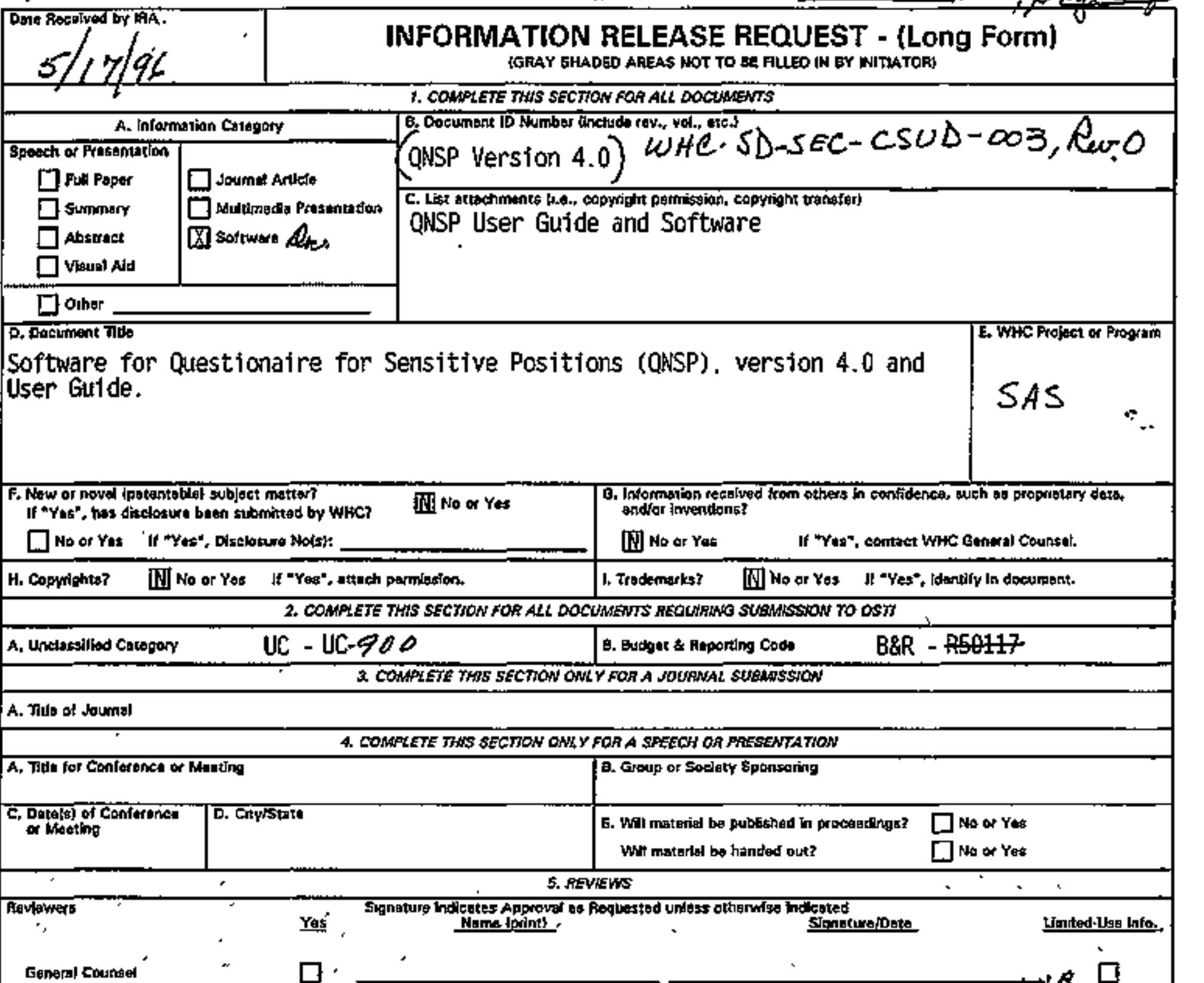

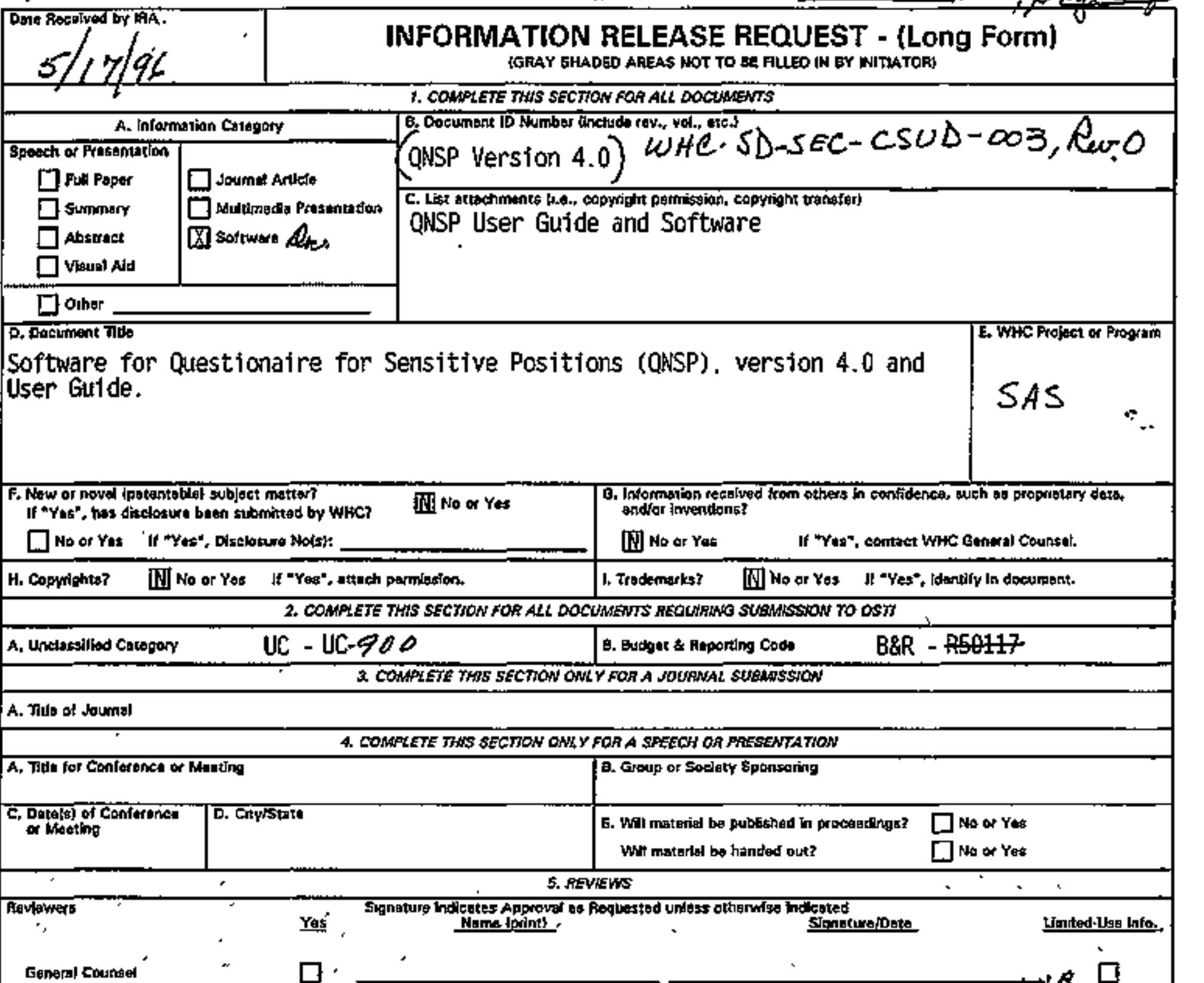

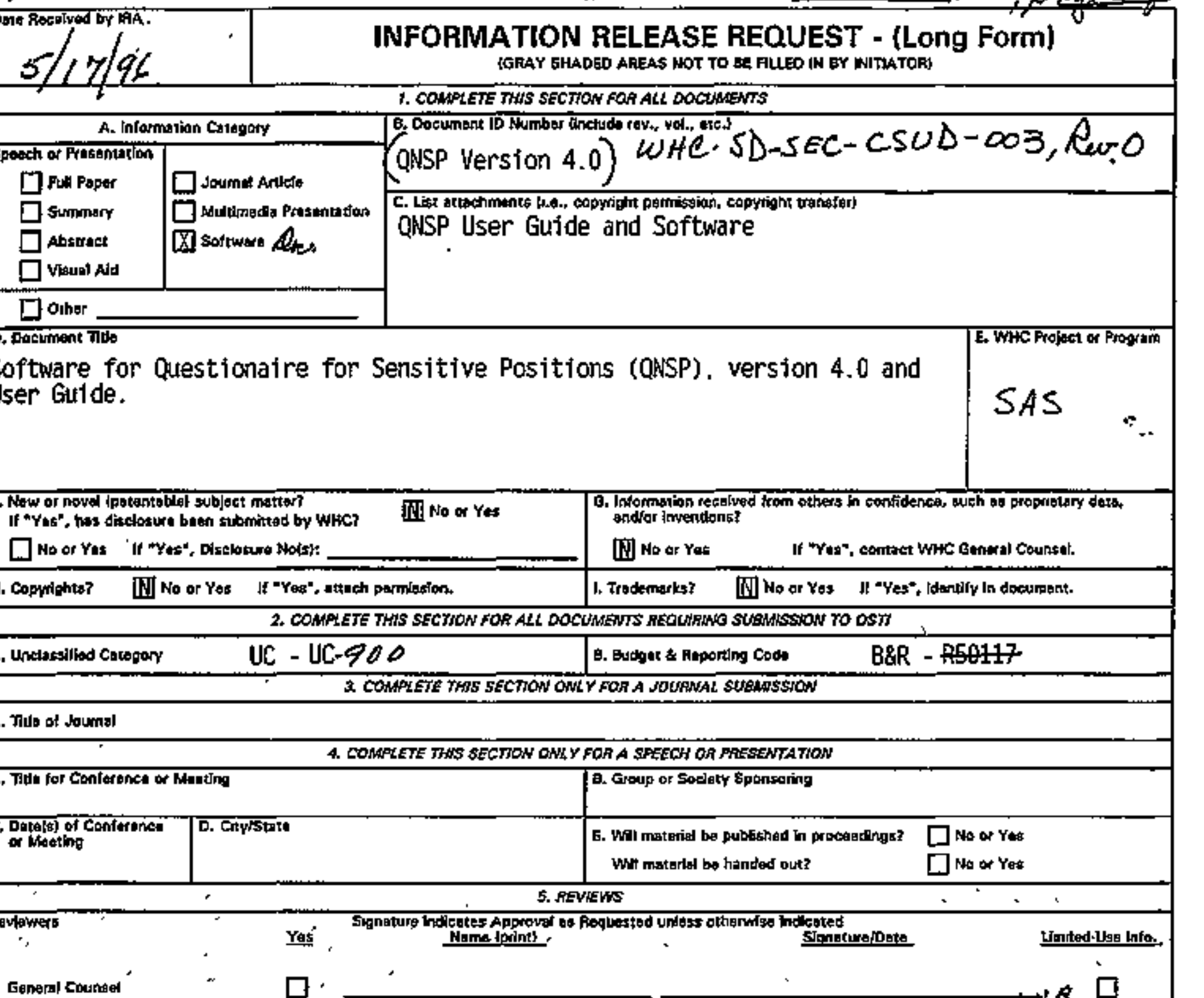

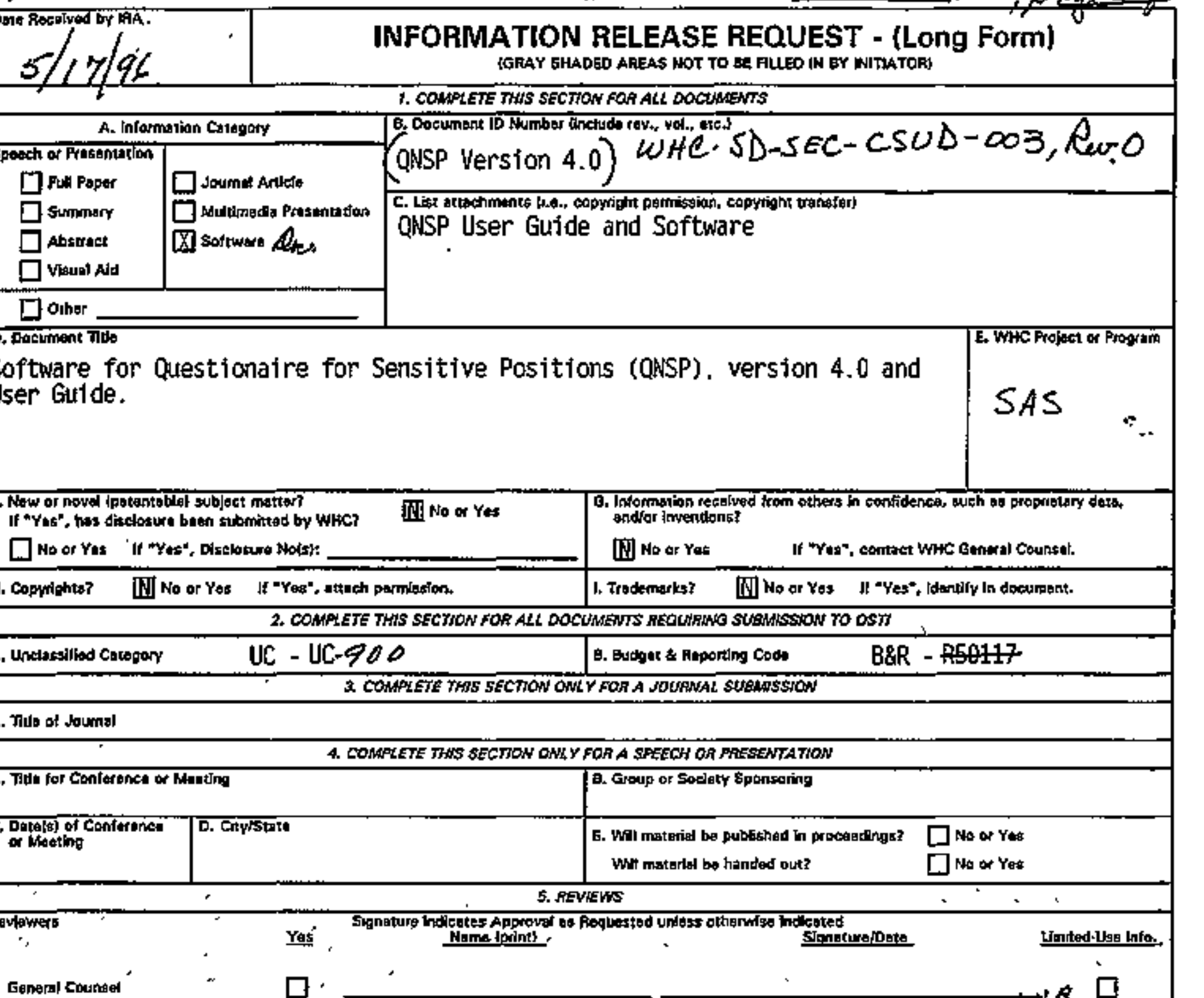

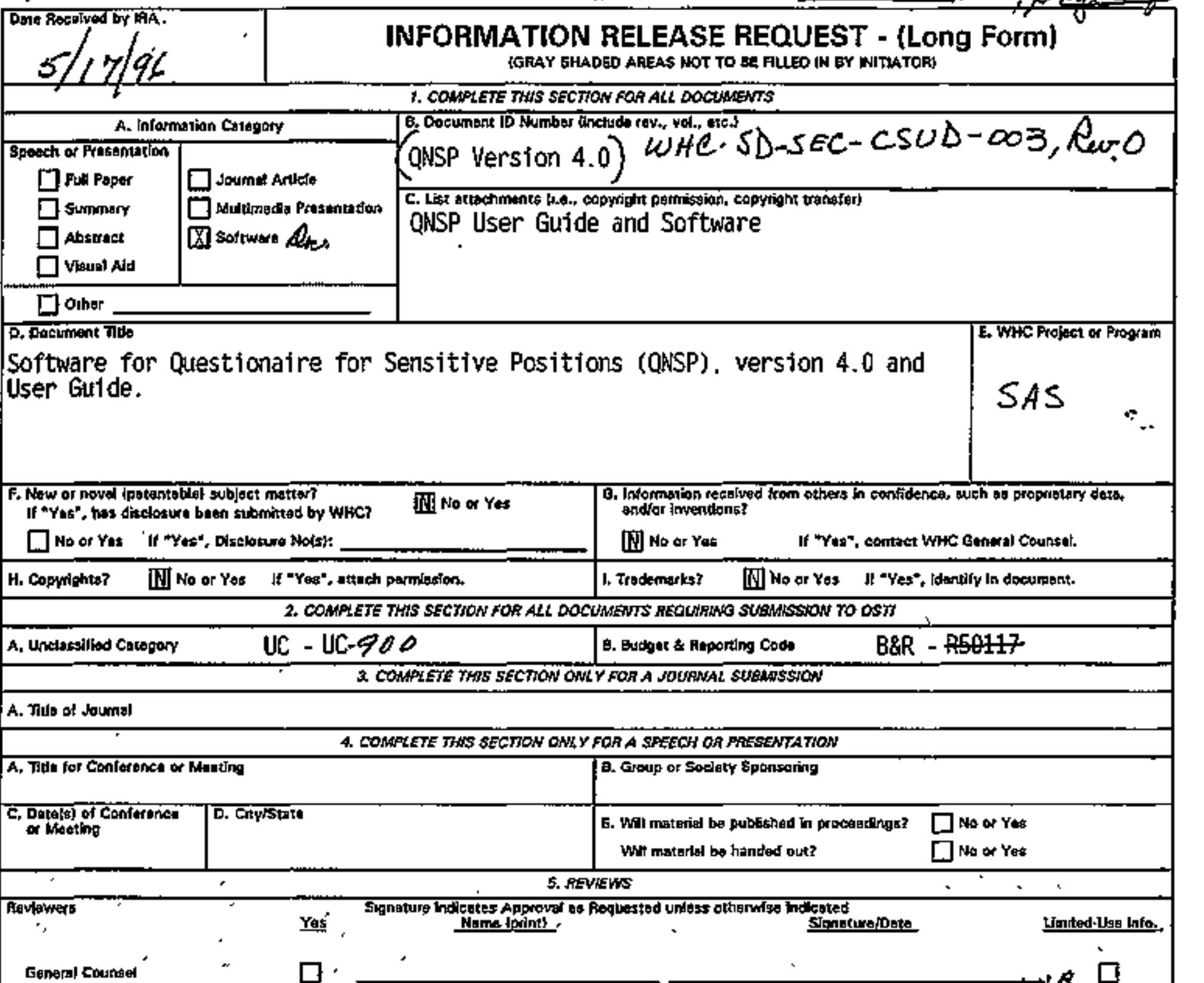

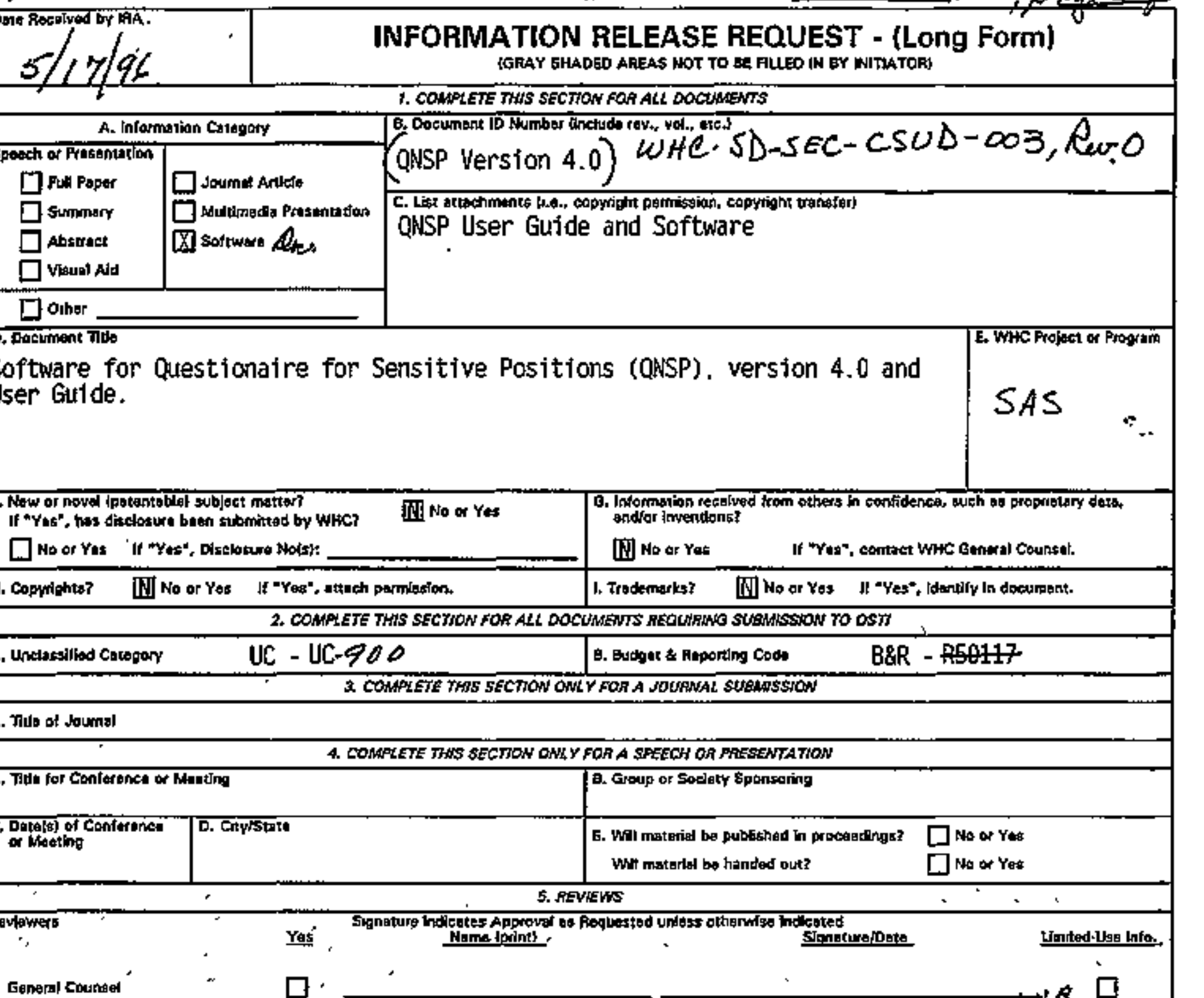

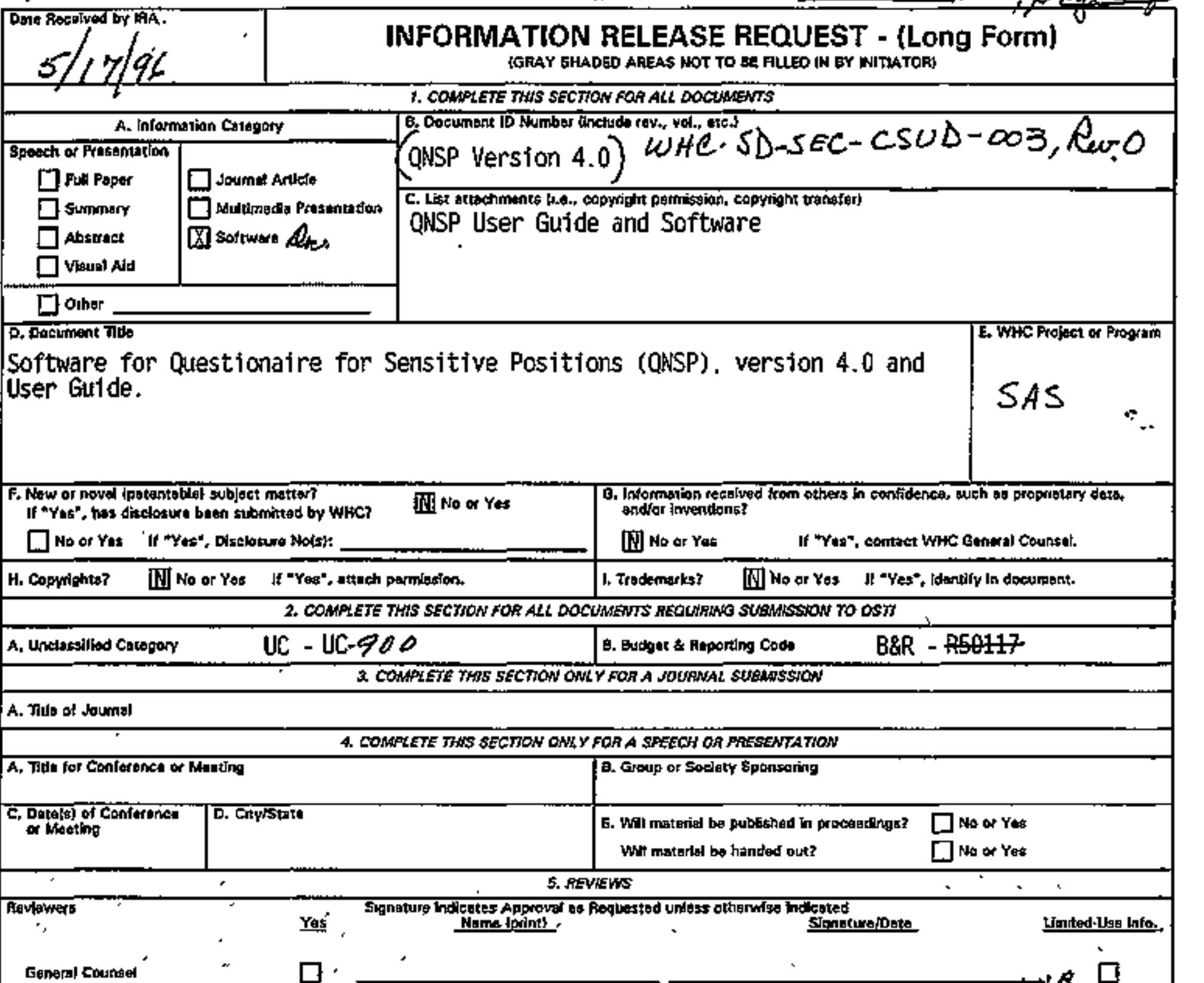

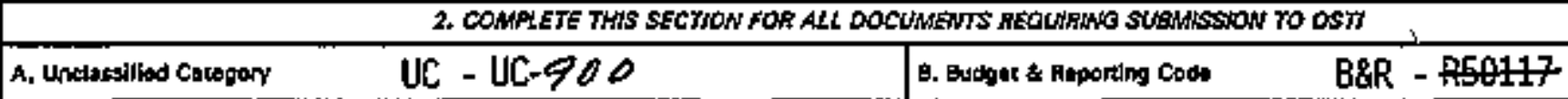

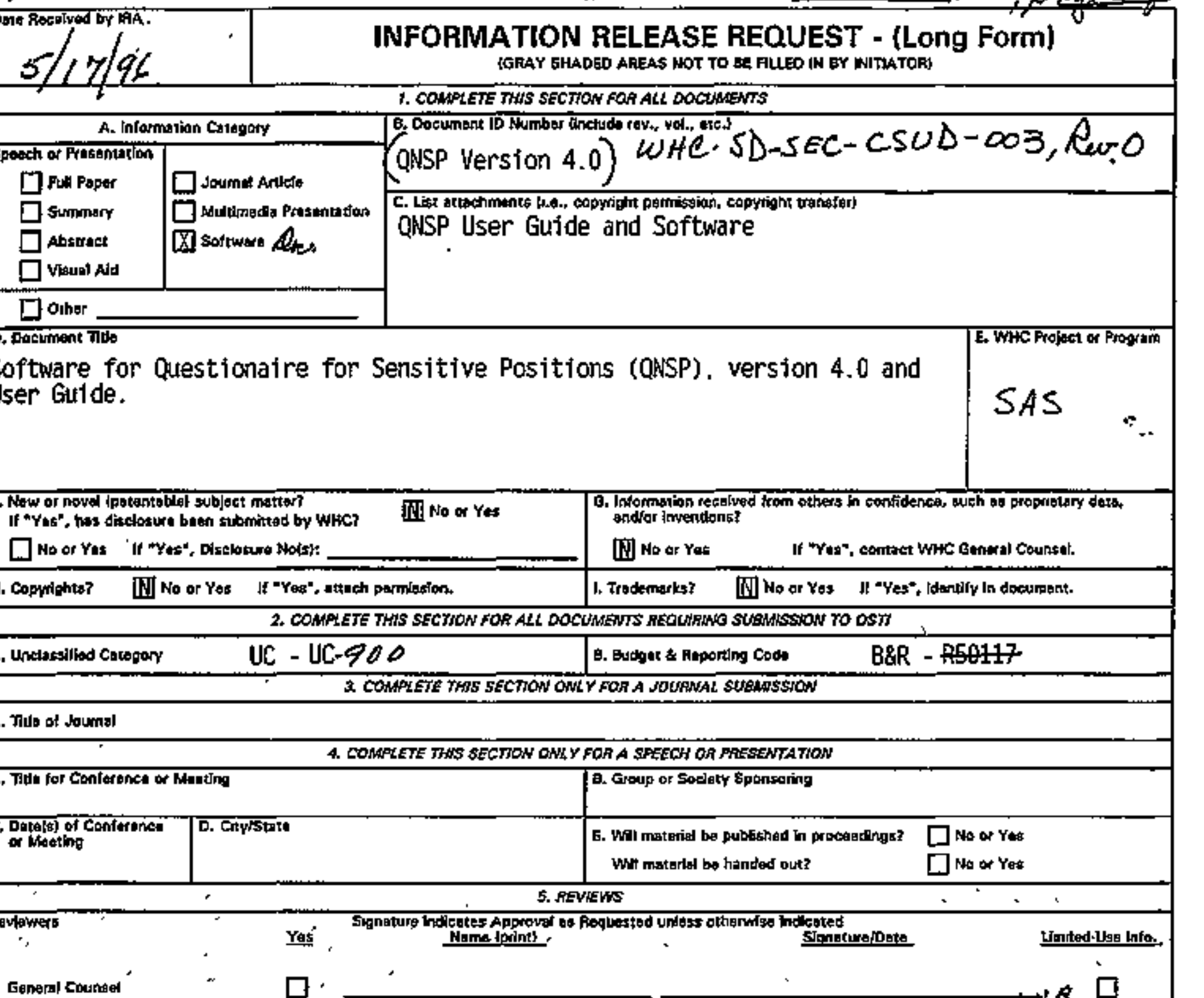

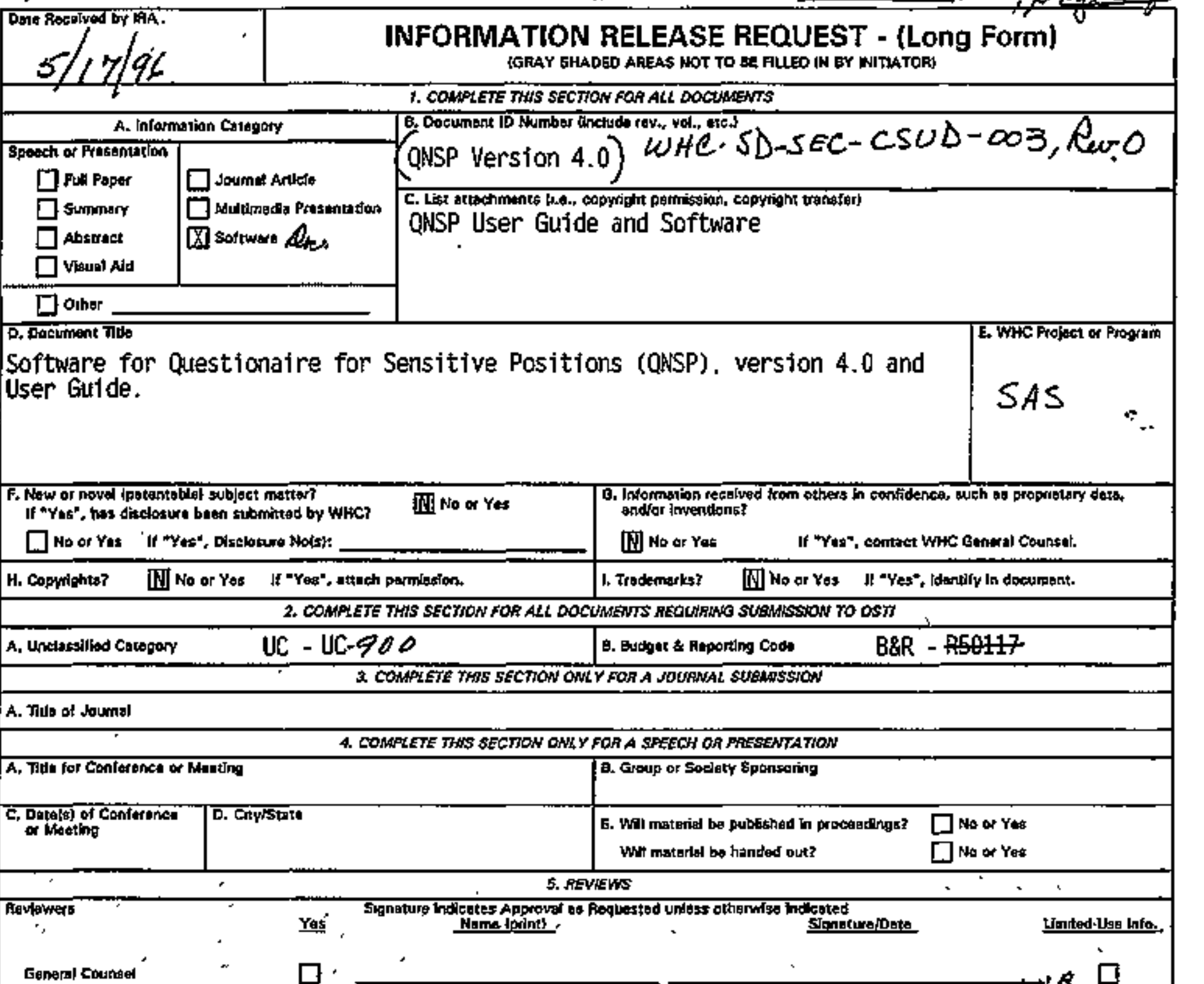

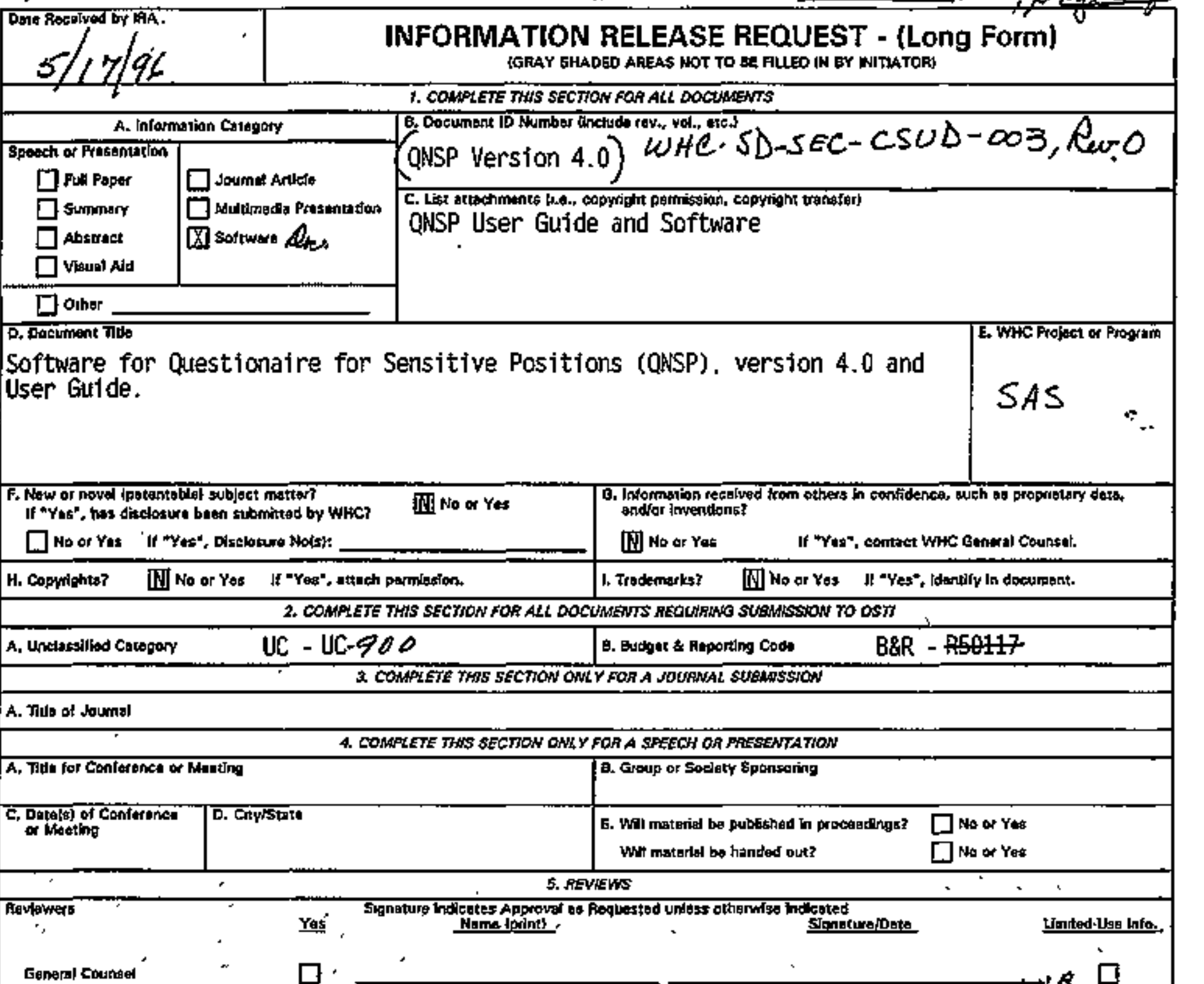

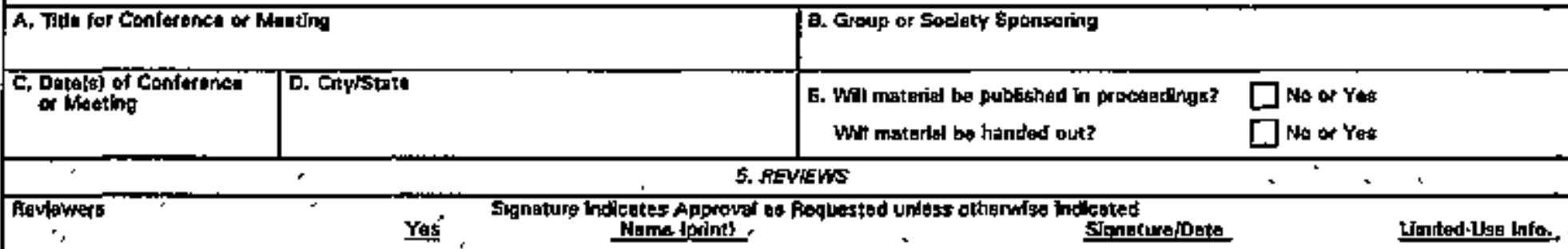

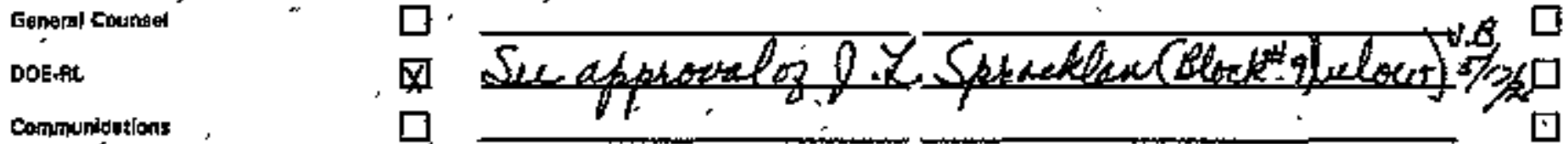

Appliad Tochnoliogr-exparic Controllod' inlormotion of internoilonil Progran'

Other

Quther

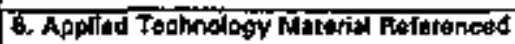

[D No $\square$ Yos

7. RARTER Lorol

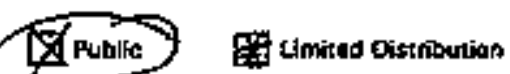
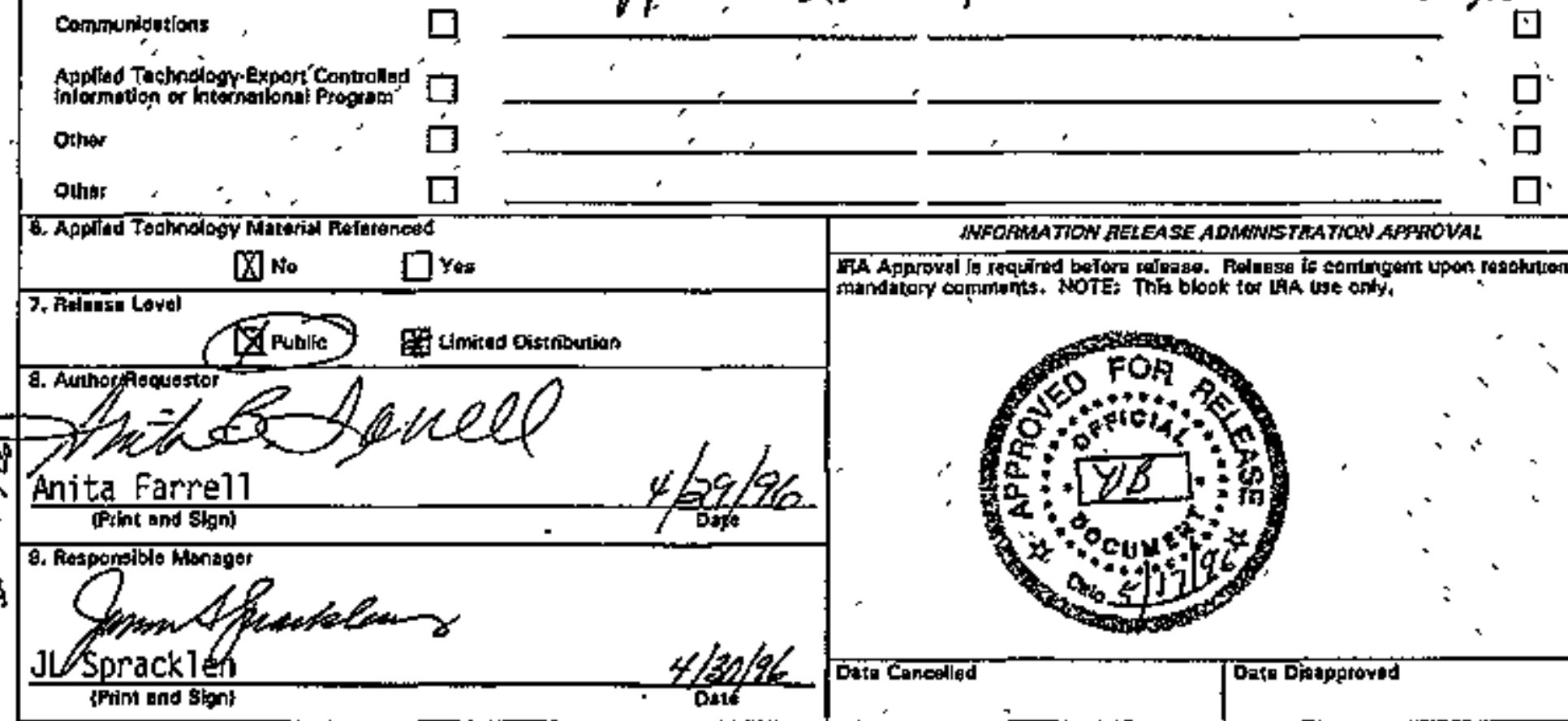

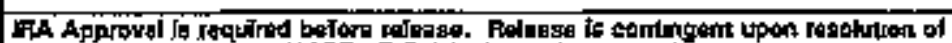

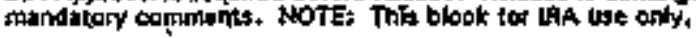

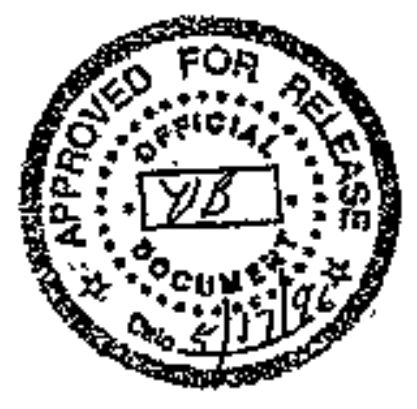

Dafe Diappiproyed 
QSP Version 4.0 User Gútide (WHC-SO-SEC-CSUD-003, Rev.0)

TABLE OF CONTENTS

1.0 OVERVIEH.

Page

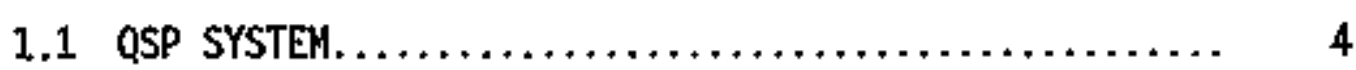

1.2 QSP VERSION 4.0 ENHANCEMENTS, ..................... 4

2.0 MAIN MENU, ...................................... 5

2.1 CHOTCES $\ldots \ldots \ldots \ldots \ldots \ldots \ldots \ldots \ldots \ldots \ldots \ldots \ldots \ldots, 5$

2.1.1 Data Entry,........................... 5

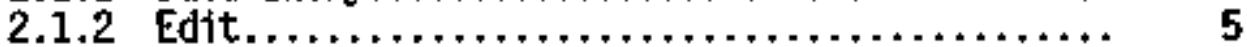

2.1.3 Print QSP Form.......................... 5

2.1.4 Archive Module $\ldots \ldots \ldots \ldots \ldots \ldots \ldots \ldots \ldots \ldots, \ldots \ldots \ldots \ldots$

2.1 .5 Utilities....................

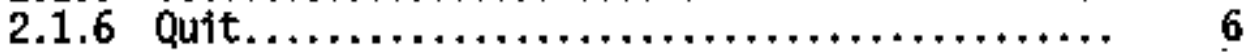

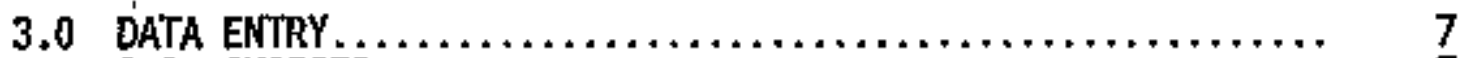

3.1 CHOICES.................................... 7

3.2 DATA ENIRY SCREEN OPTIONS................... 7

3.2 .1 F1 Key $\ldots \ldots \ldots \ldots \ldots \ldots \ldots \ldots \ldots \ldots \ldots \ldots, 7$

3.2 .2 F2 Key........,

3.2 .3 Shft-F2 Key $\ldots \ldots \ldots \ldots \ldots \ldots \ldots \ldots \ldots \ldots \ldots \ldots, 8$

3.2 .4 Esc Key $\ldots \ldots \ldots \ldots \ldots \ldots \ldots \ldots \ldots \ldots \ldots \ldots \ldots, \quad 8$

3.3 COMPLETE QSP FORM DATA ENTRY, ................. 8

3.4 PARTIAL DATA EKTRY............................ 13

3.5 PART 2 DATA ENTRY ONLY...................... 14

3.6 A.P DATA ENTRY........................... 15

3.7 QUIT $\ldots \ldots \ldots \ldots \ldots \ldots \ldots \ldots \ldots \ldots \ldots \ldots \ldots \ldots \ldots \ldots, 15$

3.8 MESSAGES FROM DATA ENTRY PROGRAHS.............. 15

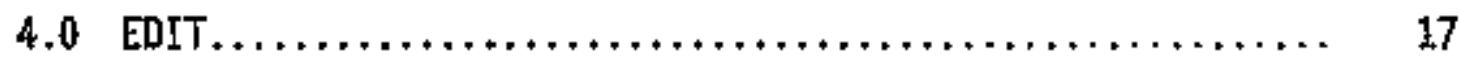

4.1 PRE-EDIT SCREEN.......................... 17

4.2 EDIT SCREEN OPTIONS........................ IB

4.2 .1 F1 Key,............................ IB

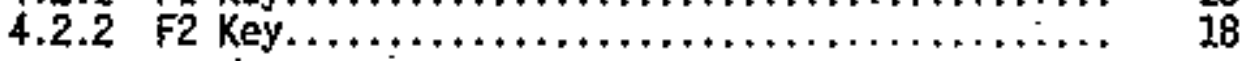


QSP Version 4.0 User Guide (WHC-SD-SEC-CSUD-003, Rev.0)

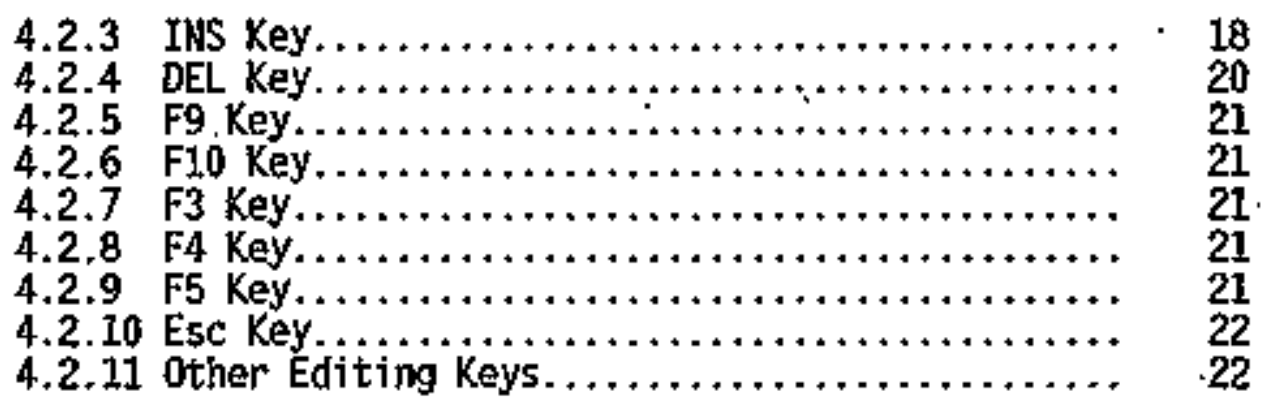

4.3 MESSAgES FROM EDIT PRGGRAM.................... 22

5.0 PRINTING PROCEDURES............................ 25

5.1 PRINT QSP FORM MENU......................... 25

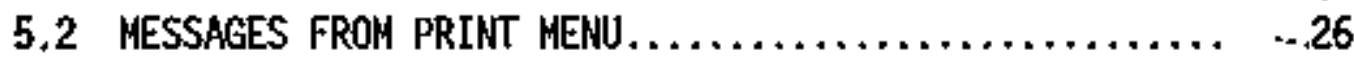

6.0 ARCHIVE MODULE, $\ldots \ldots \ldots \ldots \ldots \ldots \ldots \ldots \ldots \ldots \ldots \ldots \ldots, \quad 36$

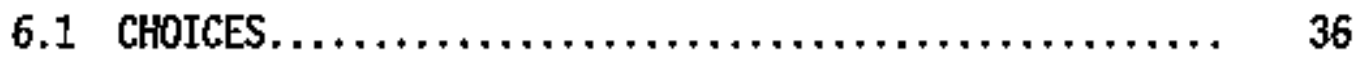

6.2 IAARK COMPLETED QSPS.......................... 36

6.2 .1 TO MARK CONPLETED QSPS.................. 37

6.2 .2 TO UNMARK COWPLETED QSPS................. 37

6.2 .3 MESSAGES FROH MARKING PROCESS.............. 37

6.3 RECALL ARCHIVED QSPS...................... 38

6.3 .1 TO RECALL $8 Y$ SSN.................... 38

6.3.2 MESSAGES FROM RECALL PROCESS............. 39

6.4 QUERY ARCHIVED QSPS $\ldots \ldots \ldots \ldots \ldots \ldots \ldots \ldots \ldots \ldots, 40$

6.4 .1 TO QUERY BY SSN...................... 40

6.4 .2 MESSAGES FROM ARCHIVE QUERY PROCESS............ 41

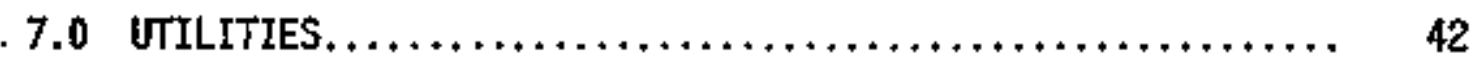

7.1 CHOICES $\ldots \ldots \ldots \ldots \ldots \ldots \ldots \ldots \ldots \ldots \ldots \ldots \ldots, \quad 42$

7.2 LOCATE GY NANE........................... 42

7.2.1 MESSAGES FRON LOCATE BY MANE PROCESS......... 43

7.3 DATE GAP CHECK. $\ldots \ldots \ldots \ldots \ldots \ldots \ldots \ldots \ldots \ldots \ldots \ldots \ldots \ldots \ldots \ldots$

7.3.1 MESSAGES FROM GAP CHECK PROCESS............ 44 If $\because 2$ 
QSP Version 4.0 User Gutide (WHC-SD-SEC-CSUD-003, Rev.0)

7.4 BLANK FIELD CHECK. $\ldots \ldots \ldots \ldots \ldots \ldots \ldots \ldots \ldots \ldots \ldots \ldots$

7.4.1 MESSAGES FROM BLANK CHECK PROCESS. . . . . . . . 46

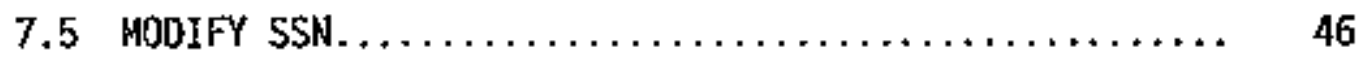

7.5.1 MESSAGES FROH MODIFY SSN PROCESS......... 47

7.6 DELETE QSP RECORDS $\ldots \ldots \ldots \ldots \ldots \ldots \ldots \ldots \ldots \ldots \ldots \ldots \ldots$

7.6.1 MESSAGES FROM DELETE QSP PROCESS .......... 48

7.7 DELETE QSP PART 2 ONLY $\ldots \ldots \ldots \ldots \ldots \ldots \ldots \ldots \ldots \ldots$

7.7.1 MESSAGES FROM DELETE QSP PART 2 ONLY....... 49

7.8 LIST ALL $Q \mathrm{SP}^{\prime} \mathrm{S} \ldots \ldots \ldots \ldots \ldots \ldots \ldots \ldots \ldots \ldots \ldots \ldots \ldots \ldots \ldots \ldots \ldots$

7.9 PRINT BLAKK QSP PACKAGE.................. 50

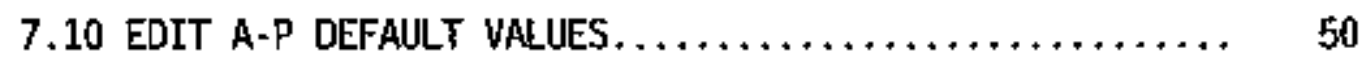

APPENDIX A QUESTIONNAIRE FOR NATIONAL, SECURITY POSITIONS FORMS. 51 
QSP Version 4.0 Uंser Gutide (WtIC-SD-SEC-CSUD-003. Rev.0)

\subsection{OVERIEW}

\subsection{QSP_SYSTEM}

The U.S. Government background investigations and reinvestigations to estabifsh that appiicants are eligible for required security clearance.

The QSP system is an automated Paradox application developed by Boeing in 1988 and used by DOE-RL for data coljectjon, retention. and printing of . facsimi le of the Standard Form 86 containing a persons data needed to conduct an investigation.

In March 1991, the QSP form was revised by the Office of the Persontul Managentent (OPW). The QSP system was modified and enhanced to QSP version 3.0 and released for use in 1992. Copies of QSP version 3.0 have been provided to approximately 20 other sites when requested. In February. 1995 the Office of the Personnel Management (OPM) approved the new form Standard Form 86 "Questionaire for Hational Security Positions". The OSP system was once again to be modified to agree with the revised form and be upgraded to QSP version 4.0.

This document describes the "how-to" process of the new QSP, released 4.0 Systern.

\subsection{VERSION 4.0 ENHANCEMENTS}

The enfianced QSP (version 4.0) system was developed by Boeing Computer Services, Richland for the Department of Energy (DOE). Richland operations office (RL). This system supports the new Questionnaire for Nationa] Security Positions (ONSP) Standard form 86 , revised September 1995. The enhanced QSP version 4.0 will replace the existing QSP systen at RL site.

This section will list and describe briefly the new features and enhancements available in QSP version 4.0 .

1 Printing - In order to better operate one shared network printer. the program will reset the Jetform format before printing each page of report, the electronic form image is merged with the data file and printed as one form. The "Load Eform" was removed from the QSP utility ments. The printout for page 11 was added into the print QSP form menu.

2 The system will print the new ONSP, standard Form 86, Revised September 1995. A blank printed out QNSP form is shown in Appendix A.

1 
QSP Version 4.0 User Guide (WHC-SD-SEC-CSUD-003, Rev.0)

3 The system now offers the capability to print continuation pages for question 9.10, and 11 .

4 A new sequential index mechanism has been added into the system. This function will help the user insert a record in edit made without having to shuffling sequential records around. In insert mode. for the multi-record type questions. the seguential record number will be begin with 01 and increment by 3 for each additional record.

5 The forniat of all date field was changed to include the "/" separator character.

6 The system will default in the following fields in items A.P: L. N, $P$ (Name). P(Phone).

7 The duplicate key exist routine has been modified to prevent the system lockup. 
QSP Verstion 4.0 (User Gitide (HHC-SD-SEC-CSLD-003, Rev.0)

\subsection{MAIN RENU}

\subsection{CHOICES}

DATA ENTRY EDIT PRINT QSP FORIT ARCHIVE MOOULE UTTLITIES QUIT

The above is the QSP Main Menu that appears at the top of the screen. To select any of the choices, the user may either highlight the choice by moving to it using the cursor keys or by typing the first letter of the choice. The following briefly describes each selection.

\subsubsection{DATA ENTRY}

This selection allows the user to enter new QSP records -in two modes: Complete QSP Form Data Entry and Partial Data Entry. When entering a new OSP Packet from the beginning. the user wotild choose "Complete QSP Form Data Entry". It starts on Page 1. Item A and cont $\neq$ nues through the rest of the form until the user exits out the data entry mode. If, for some reason, the data entry could not becompleted in one session, the user may select "Data Entry" then seiect "Partial Data Entry". This mode would allow starting the data entry process at a particular question number and continuing on froti that question. An additional data entry mode. "A-P Data Entry" limits data entry to just Items A through P on Page 1.

\section{$2,1.2$ EDIT}

This selection allows the tuser to fetch and possible change data based on soctal secterity number (SSH) which is the key fieid in this application and a quest ton number. ATl fields are changeable except for SSN.

\section{1 .3 PRINT OSP FORN}

This selection allows the user to selectively print all or selected QSP form. page for a SSN. The data may come from either the Active or Archive data tables.

\subsubsection{ARCHIVE MODULE}

This selection allows the user to: a) Nark or unmark a QSP as completed. b) Recal) a selected archived QSP from the Archive data tables to make it active again, c) Query information from archived QSPS. 
QSP Version 4.0 User Giuide (WHC-SD-SEC-CSUD-003, Rev.0)

\subsubsection{UTILITIES}

This selection allows the user to: a) Locate a person in the OSP system by name if SSN is not known, b) Check questions with date ranges ' for gaps. c) Check any or" ail questions for blank data fields, d) Modify an erroneously entered SSN to fix it. e) Delete a QSP from the system partialiy or entirely. f) Produce a listing of SSN and Names of a 17. OSP's that have been entered into the system, g) Print a complete 13 page blank QSP package. h) Edit default field values in Items A-P located on Page 1.

\section{1 .6 QUIT}

This selection invokes the exit process out of the QSP application and the PARADOX software.

$$
1
$$$$
-7
$$ 
QSP Version 4.0 User Guide (WHC-SD-SEC-CSWD-0103, Rev.0)

\subsection{OATA ENTRY}

\subsection{CHOICES}

COMPLETE QSP FORM DATA ENTRY PARTIAL DATA ENTRY A-P OATA ENTRY QUIT

The above will appear at the top of the screen. To select any of the choices. either highlight the choice and press Enter key or type in the first letter of the choice.

\subsection{DATA ENTRY SCREEN OPTIONS}

F1-ST Lookup F2=Save \& Display Next Blank Record

Shft F2=Save \& Display Next Question ESC-Cancel Data Entry

The above will appear at the top of all data entry screens. Each choice refers to a keypress the user may use during a data entry session. They may all be pressed at any time with the exception of the Fl key (see below). The following briefly describes each option.

\subsubsection{E1 Key}

A PARADOX feature was utilized in this application. It is called "Help and Fill". All valid 2 digit abbreviations for US states and territories have been stored in a lookup table. Each entry in a state field is verjfied against this lookup table. If no match is found (invaiid state WX) the message "Not one of the possible values for this field" will be displayed. By pressing the FI key. the state Tookup tabie wili be displayed. The user may then cursor down to the desired abbreviation and press the $F 2$ key. This will cause PARADOX to fill:in the state field with the desired abbreviation automatically. The F1 key may be used only when the cursor is in a "State" fieid.

\subsubsection{E2 Key}

This is bastcally a record "save" key. Whenever this is used. the current record image is saved and stored in the table. In the case of multiple record questions such as $\$ 9, \ldots 10$, $\# 11$. it is used to save the "just entered" record to the respective data file and create and display a new biank record for that same question. When the maximum number of records for a question has been reached, the use of the F2 key wi?l save the "just entered" record and advance the user to the next page/question.

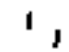


QSP Version 4.0 User Guide (WHC-SD-SEC-CSUD-003, Rev.0)

\subsubsection{Shft.F2 Key}

This is the "save" key for a whole question. It acts the same as the F2 key by saving the current record image but instead of displaying the next biank record for the same question. it advances the user to the next question in succession. If. for example, a user has entered 2 employment records (question $\# 11$ ) and has just filled-in a third, the Shft-F2 key would save the third employment record image and advance the user to Question \#12.

NOTE: When entering data in a multiple page screen be sure to use the Pageln key to view all screens before pressing Shft- $\$ 2$.

\subsubsection{ESC Key}

This key does not save the current record inlage. It wi11 return the user to the previous menu. It may be pressed ạt any time.

\subsection{COMPLETE OSP FORM DATA ENTRY}

1. Items A-P - This is a multiple page screen.

a. Fill-1n the blank data fields as required.

b. Use PageUp/PageDn Xeys to view all screens.

c. Press F2 key to advance to Question $\|^{1} 1$ on Page 1.

d. HOTE: The system will supply default values in the following fields: L - "DN04". N - "89002001", P(Name) - "Dennis G. Sieracki, Chief, PSB", P(Phone) - "(509) 376-6854"

2. Questions $\$ 1-8 \mathrm{e}$ - This has a multiple page screen.

a. Fill-in the blank data fields as required.

b. Use Pagetup/Pagebn keys to view all screens. (Quest. 8 has been reordered on the screen. It appears in the following order: 8a, 8b, 8d, 8c, 8e.)

c. Press Shft-F2 key to advance to Question $\$$ H9 on Page 2.

d. MOTE: If Question 3 (Country of Birth) is left blank, the systen will supply a defaut t value of 'USA'.

e. NOTE: SSH and Mother's Maiden Name are required entries. If they are left biank. the user will not be permitted to proceed to the next question.

I 
QSP Version 4.0 User Guide (WHC-SB-SEC-CSU0-003, Rev.0)

3. Question 战 RESIDENCES - This is a multiple record question.

a. This has a multi-record screen which allows the user to view more than one record at a time.

b. Maxinum number of records per SSN: 99

c. Fill-in the blank data fielơs as required.

d. Press FZ key after each individual record to receive next new blank record.

e. Press Shft.F2 key after the last residence record has been tyoed. This will advance user to Question $\{10$ on Page 2.

f. NOTE: AII ZIP Code fields have been expanded to accept ZIP+4, and they will also accept alpha characters for foreign addresses.

4. Question $\$ 10$ SCHOOLING - This is a multiple record question.

a. This has a multi-record screen which allows the user to view more than one record at a time.

b. Maximum number of records per SSN: 6

c. Fill-in the blank data fielos as required.

d. Press F2 key after each indivioual record to receive next new blank record.

e. Press Shft-F2 key after the last school record has been typed. This will advance user to Question \#11 on Page 3.

$f$. NOTE: If the user needs to enter more than six records, those must be entered on the CPX Continuation Page as the SF86A Continuation Sheet no longer contasns space for this question.

5. Question f11 EMPLOYMENT - This is a gultiple record question.

a. This has a multij-table screen which allows the user to view or enter the period of employment with an emplayer.

b. Maximum number of previcus periods of emiployment records per company: 3

c. Fill-in the blank data fields as required.

d. Press F2 key after each individual record to receive next new blank record.

e. Press Shft-F2 key after the last employment record has been typed. This will advance user to Question \#12 on Page 4.

6. Question \#12 REFERENCES -

a. One record holds 3 complete references.

b. Filli-in the blank data fields as required.

c. Use Pagelup/Pageln keys to view all screens.

d. Press Shft-F2 key to advance to advance to Question $\$ 13$ on Page 5. 
QSP Verston 4.0 User Guide (HAC-SD-SEC-CSUD-0.03, Rev.0)

7. Question 13 MARITAL STATUS -

a. Fill-in the blank data fields as required.

b. Use Pagellp/PageDn keys to view al] screens.

c. Press Shft-F2 key to advance to Question $N_{114}$ on Page 5.

d. MOTE: "Coumtry of Citizenship". if left blank, will default to 'USA'.

8. Question \#14 YOLR RELATIVES AND ASSOCIATES - This is a multiple recoro question.

a. This has a multi-record screen which allows the user to view more than one record at a tíme.

b. Maximalm number of records per SSN: 12

c. Finl-in the blank data fields as regutired.

d. Press F2 key after each individual record to receive next new blank record.

e. Press Shft-F2 key to advance to Question \#15 on Page 6. "

9. Question 15 CITIZENSHIP OF RELATIVES AND ASSOCIATES -

a. One record holds 2 complete associations.

b. Fill-in the blank data fielos as required.

c. Press F2 key after each individual record to receive next new blank record.

d. Press Shft-F2 key after the last reference record has been typed. This will advance user to Question "\#16 on Page 6.

10. Question \#16 MILITARY HISTORY - This is a muiti-record question.
a. This has a multi-record screen which allows the user to view more than one record at a time.
b. Question $\$ 16 a$ - Fill-in the blank data fields as requtred.
c. Question $* 16 b$ - Fill-in the blank data fields as required.
d. Naximus number of records per $S S N: 2$
e. Press f2 key after each individual record to receive next new blank record.
f. Press Shft.F2 key after the last active service record has been typed. This will advance user to Question \$17 on Page 6.
g. NOTE: Code 7 for National Guard now requires a two digit state abbreviation to be filled in.

II. Question \#17 FOREIGN ACTIVITIES -
a. Fill-in the blank data fields as required.
b. Use Pagellp/PageDn keys to view all screens.
c. Press Shft-F2 key to advance to Question \$18 on Page 6. 
QSP Version 4.0 User Guide (WHC-SD-SEC-CSUD-003, Rev.0)

12. Question \#18 FOREIGN COUNTRIES -
a. Fill-in the blank data fields as required.
b. Press F2 key after each individuã 1 record to receive next new blank record.
c. Press Shft-F2 key after the last country record has been typed This will advance user to Question $\# 19$ on Page 7.
d. MOTE: The user may indicate more than one purpose for a visit to a foreign country by separating the purpose codes with a comna. e.g.. . $' 1,2$ '.

13. Question \#19 MILITARY RECORO -
a. Fili-in the blank data fields as required.
b. Press Shft-F2 key to advance to Question $\$ 20$ on Page 7.

14. Question \$20 SELECTIVE SERVICE -
a. Fill-in the blank data fields as required.
b. Press Shft-F2 key to advance to Question $\$ 21$ on Page 7.

15. Question *21 BEDICAL RECORD -
a. Fill-in the blank data fields as required.
b. Press Shft.F2 key to advance to Question $\$ 22$ on Page 7.

16. Question 222 EMPLOWMENT RECORD -
a. Fili-jn the blank data fields as required.
b. Press Shft-F2 key to advance to Question $\$ 23$ on Page 7.

17. Question \#23 POLICE RECORO -
a. Fill-in the blank data fields as required.
b. Use Pagelo/Page0n keys to view all screens.
c. Press Shft-F2 key to advance to Question $\$ 24$ on Page 8.

18. Question \$24 ILLEGAL DRUGS AND DRUG ACTIVITIES -
a. Fill-in the blank data fields as required.
b. Use Pagelup/Pageon keys to view all screens.
c. Press Shft.F2 key to advance to Question \#25 on Page 8.

19. Question \#25 USE OF ALCOHOL -

a. Fill-in the blank data fields as required.

b. Use Pagelyp/Pageon keys to view all screens.

c. Press Shft.F2 key to advance to Question $\$ 26$ on Page 8.

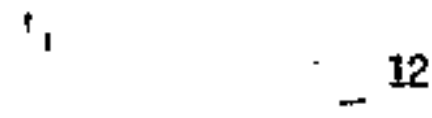


QSP Version 4.0 User Guide (WHC-SD-SEC-CSUD-003, Rev.0)

20. Question \#26 INVESTIGATIONS RECORD -

a. Fill-in the blank data fields as required.

b. Use Pagellp/Pageln keys to view all screerns.

c. Press Shft-F2 key to advance to Question \$27 on Page 8.

21. Question \#27 FINANCIAL RECORO .

a. Fill-in the blank data fields as required.

b. Use Pagelp/Pagehn keys to view all screens.

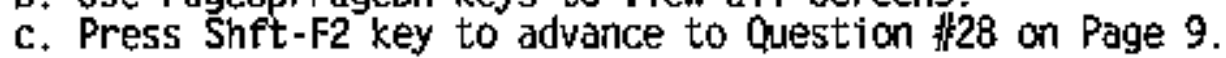

22. Question "W28 FINANCIAL DELINQNENCIES -

a. Fill-in the blank data fields as required.

b. Use Pagelup/PageDn keys to view all screens.

c. Press Shft.F2 key to advance to Question \#29 on Page 9 .

23. Question \#29 PUBLIC RECORO CIVIL COURT ACTIONS -

a. Fili -in the blank data fields as required.

b. Use Pagelp/Pagên keys to view all screens.

c. Press Shft-F2 key to advance to Question fif30 on Page 9.

24. Question $\# 30$ ASSOCIATION RECORO -

a. Fill-in the blank data fields as required.

b. Press Shft.F2 key to advance to the Continuation space on Page 9.

25. PAGE 9 COATINUATION SPACE - This is a multiple record item.

a. This is a multi-record screen which allows the user to view more than one record at a time.

b. Maximum number of records per SSN: 9

c. Fill-in the blank line as required. Format is free form. Data field is displayed as two 65 character lines on the screen. This will be printed as one 130 character line on the form.

d. Press F2 key after each individual record to receive next new blank record.

e. Press Shft-F2 key after the last continuation record has been typed.

f. If more continuation pages are needed, go to step 25 , otherwise press Esc to end data entry session. 
QSP Version 4.0 User Guide (WAFC-SD-SEC-CSLO-003, Rev.0)

26. CONTINIATION SHEET (CPX) - This is a multiple record item.

a. This is a multi-record screen which allows the user to view more than one record at a time.

b. Maximum number of recoräs per SSN: 36

c. Fill-in the blank line as reguired. Format is free form. Data field is oisplayed as two 65 character lines on the screen. This will be printed as one 130 character line on the form.

d. Press F2 key after each individual record to receive next new blank record.

e. Press Shft-F2 key after the last continuation record has been typed. User is returned to Data Entry Ments.

27. MOTE: The date fields (those specifying Wonth/Year) are 6 character fields; enter $M M / Y Y$. The extra byte is avai lable for the user to enter any special character, e.g.. '*', either before or after the date, in order to indicate that the person is simply not.sure of the exact date. In other words, this date is approximate.

\subsection{PARTIAL DATA ENTRY}

This node can only be used when a question has had nothing entered in it initially. If the user needs to add new records to an existing question. use the Insert option in the EDIT mode. (see 4.2.3 INS Key)

\section{PARTIAL DATA ENTRY MODE}

Enter Social Security Number.:

Enter QSP Question Number...

1. To cancel edit; press ESC key.

2. Blank SSH will activate Name Search.

3. For cont. pages, Question no. $C P 1=\mathrm{Pg}$. 9. $\mathrm{CPX}=$ Extra Pages.

1. At the Partial Data Entry Screen, enter employee's SSN. (Blank SSN activates the Name Search Utjlity: Esc key will cance] data entry and rettern to Main Menu.)

2. Program will verify entered SSN against QSP Master Table (QST_1-8).

3. If entered SSN is not found, a message indicating such is displayed and the SSA will have to be re-entered. 
QSP Version 4.0 User Guide (UHC.SD-SEC-CSUD-003, Rev.0)

4. If entered SSN is marked as completed, this process is canceled and the user is returned to the Data Entry Menu.

5. If entered SSN is valid. the user is prompted for question number. (Blank question number will cause program to loop up and prompt to re-enter SSN.) NOTE: This entry is case sensitive.

6. Program will verify entered guestion no. against a jookup table that has all valid question numbers in it.

7. If the entered question number is invalid, a message indicating such is displayed and the user will have to re-enter the question number.

8. If the entered question no. is valid. the data entry screen will be displayed and will act the same as if the user were in the Complete Data Entry mode.

\subsection{PART_2DATA_ENTRY ONLY}

This procedure can be used to enter just Part 2 data if the persen has NOT been previously entered. If a person has been previously entered, use the Edit mode to view the QSP data question number by question number.

1. At the Data Entry Menu Screen, select CONPLETE QSP FORM DATA ENTRY and press Enter key.

2. When a blank Page 1 is displayed. type the information required.

3. Program will verify entered SSN against QSP Master Table.

4. When done with Page 1. press Shft-F2 keys to save Page 1 data.

5. Press Esc key to return to Data Entry Menu Screen.

6. Select PARTIAL QSP FORM DATA ENTRY and press Enter key.

7. At the prompt. type person's SSN and press Enter key.

a. At the question number prompt. type 19 and press Enter key. (Question 19 is the first question of the Part 2 section on Page 7.)

9. The user may now input Part 2 data in blank record displayed on the screen. The rest of the Part 2 section (Pages $8 \& 9$ ) will follow as the user presses Shft-F2 upon the completion of each page.

10. To cancel and return to Data Entry Menu Screen. press Esc key. 
QSP Version 4.0 User Guide (WHE-SD-SEC-CSLD-003, Rev.0)

\subsection{A-P DATA ENTRY}

This procedure can be used to enter just Items A-P data if the person has no A-P data has been previously entered. If data has been previously entered. use the Edit mode to view the items by entering "AP" as the question number.

1. Select A-P DATA ENTRY and press Enter key.

2. At the prompt. type person's SSN and press Enter Key,

3. Program will verify entered SSN agajnst QSP Master Table.

4. If entered SSN is not found. a message indicating such is displayed and the SSN will have to be re-entered.

5. If entered $\$ S \$$ is marked as completed. this process is. canceled and the user is returned to the Main Menu.

6. If entered $S S N$ is valid, the program will search for an existing A-P QSP record. If not found there. new entry is assumed and the data entry screen with blank record is displayed.

7. The user may now input $A-P$ data in blank record displayed on the screen. The data entry is limited to just Items $A$ throwgh $P$. When done. press F2 key.

8. To cancel and return to Oata Entry Menu Screen, press Esc key.

\subsection{QUIT}

This selection will take the user back to the Main Menu.

\subsection{MESSAGES FROM OATA EATRY PROGRAUS}

1. "DUPLICATE SSA FOUND ON FILE... USER MNST MOOIFY SSN TO INPUT NEN RECORD. OR ESC TO CAKCEL RECORD ENTRY... PRESS ANY KEY TO CONTINUE

CAUSE: An attempt was made to enter a new QSP with a SSH that is already in the QSP Master table.

USER ACTION REQ'D: Press any key to receive further instructions. 
QSP Version 4.0 User Guide (WHC-SD-SEC-CSUD-003, ReV.0)

2. "This Social Security Number is not found in Master Table (QST_1-B)"

CAUSE: From Partial Data Entry mode. the entered SSN was not found in the QSP Master table (QST 1-8) when the verify process was done. Only SSN's matching existing SSN's in the QSP Master table are allowed.

USER ACTION REQ:D: None. Program will automatically loop back to allow user to re-enter SSN or exit.

3. "Not one of the possible values for this field"

CAUSE: A number not matching the valid question numbers was entered.

USER ACTION REQ'D: None. Program will automatically allow user to . re-enter question number.

4. "Record(s) exists. . Use EDIT Mode to enter more or to view..."

CAUSE: From Partial Data Entry mode. one or more records matching the entered SSN currently exist for the desired question. Perhaps the user had previously entered one record in a multi-record question and is now trying to use Partial Data Entry mode to enter more records for that question. In any case, the EDIT mode must be used to view what has previously been entered.

USER ACTION REQ'D: 1 . Press any key which will cause prograra to loop back to allow user to re-enter SSN and question number.

2. Qtit out of DATA ERTRY mode and seject EDIT to view records.

5. "This QSP is marked as corrpleted \& archived...Cancel..."

CAISE: When the entered SSN was being validated, the Date Archived field was non-blank indicating a completed/archived QSP.

USER ACTION REQ'D: 1. Press any key. The program will continue on. Note: This QSP may be recalled from the Archive tables (see Sec 7.3) if it has indeed been archived. Otherwise, the user may unmark the QSP by following Sec. 7.2. 
QSP Version 4.0 User Guide (WHIC-SD-SEC-CSUD-003, Rev. B)

\subsection{EDIT}

\subsection{PRE-EDIT SCREEN}

\section{E DI T HODE}

Enter Social Security Number:

Enter QSP Question Number...:

1. To cance 1 edit, press ESC key.

2. Blank SSN will activate Name Search.

3. For cont. pages, Question no. $C P 1=P g .9 . C P X=$ Extra Pages. For Pgl items A-P. Use 'AP'.

1. Enter employee's SSN. (Blank SSN activates Nane Search Utility. Esc key will cancel edit mode and return to Main Menu.)

2. Program will verify entered SSN against QSP Master Table.

3. If entered SSN is not found, a message indicating such is displayed and the SSN will have to be re-entered.

4. If entered SSH is marked as completed, this process is canceled and the user is returned to the Main Menu.

5. If entered SSH is valid, the user is prompted for question number. (Blank question number will cancel edit mode and return to Main Menu.) NOTE: This entry is case sensitive.

6. Progran will verify entered question no. against a lookup table that has all valid question numbers in it.

7. If the entered question number is invalid, a message indicating such is displayed and the user will have to re-enter the question number.

8. If the entered question number is valid, a check is made to see if a record exists for that question.

9. If a record exists, the record will be displayed.

10. If no record exists for that question, the following prompt will be displayed:

"Do you wish to insert data for this question ? $(Y / N)$ " 
QSP Version 4.0 User Guide (WHC-SD-SEC-CSUD-003, Rev.0)

\section{I PRE-EOIT SCREEN}

A "yes" answer will invoke an insert process similar to the data entry process that will al low the user to enter data just for that one question (see 2.0 DATA ENTRY for explanation of options and keys). A "no" answer will prompt the user to re-enter the question number.

\subsection{EOIT SCREEN OPTIONS}

ESC=Cance1 $\mathrm{F2}=$ Done/Save INS=Insert new Seg rec DEL=Delete rec $\mathrm{F} 1=\mathrm{St}$ Lookup $\mathrm{FG}=\downarrow$ Rec $\mathrm{F} 10=\uparrow$ Rec $\mathrm{F} 3=\uparrow \mathrm{Tbl} F 4-\downarrow$ Tbl F5=Date Gap Chk CTL-F Field Edit

The above will appear at the top of all data entry screens. Each choice refers to a keypress the user may use during an edit session: They may ail be pressed at any time with the exception of the Fl key (see below). The following briefly describes each option.

\subsubsection{F1 Key}

Same as 2.2.1 F1 Key.

\section{2 .2 F2 KeV}

This is the record "save" key. This key would save all changes made to the current record image. It will return the user to the Pre-Edit Screen.

\subsubsection{INSKEy}

Upon pressing this key a check is made to see if question is a multiple record type. If it is, it will allow the jnsert process to continue: otherwise, a message will be displayed informing the user that the insert attempt will not be allowed.

NOTE: Only 1 insert record per INS keypress, except Question \#11.

The following outlines the insert process.

YES

Proceed with Insert

No

Cance] Insert

1. The above is displayed when the INS key is pressed and is a safety check in case of an errant keystroke. 
QSP Version 4.0 User Guide (WHC-SD-SEC-CSUD-003, Rev.0)

2: A "no" answer will oisplay the following message: "Insert canceled...Press ENTER key." The insert process is canceled and returns the user to the Edit screen.

3. A "yes" answer will prompt the user with the following:

"Social Security Number is $x x x \cdot x x-x x x x$

Enter New Record Sequence Number:

(Blank numer or ESC key will cancel insert)" " was O1)

4. Fill-in the sequence number blank with the next sequential recoro number. Except for question 311 . the record sequence number is a 2digit number: use leading zeroes on sequence numbers 1-9. For example, if there are 2 school records (Question $\| 10$ ) existing, and the user wishes to enter a third. then the record sequence number would be " 03 ".

5. Several checks will take place upon entering the recorid sequence number:

lst - Check for blank sequence number. If blank. program will return user to Edit screen.

2nd - Check for maximum sequence number for that question. If the question is a multiple record type. the program witl check to see if the sequence number entered is greater than the maximum number set for that question. If it is greater than, an error message is displayed (see 4.2.9) and the user will have to re-enter it or exit with a blank number. If it is less than the maximum allowed, the program wi11 accept it.

3rd - Check for existing record with the entered SSA and record seguence number. If a record does exist, an error message is displayed (see 4.2.9) and returns user to the Edit screen. If none exists. a new blank record is created and displayed.

6. A new menu appears at the top of the screen:

F1 = ST Lookup F2 = Done/Save ESC = Cancel Insert/No Save

These keys perform the same ftmctions as has been previously described. Fitl-in the data fields as required.

7. If $F 2$ key is pressed, the program will save the new record and it witi be the current record image when the user is returned to the Edit screen.

8. If Esc is pressed, the user will be retumed to the record image that was displayed before the INS key was pressed.

$$
\because 20
$$


QSP Version 4.0 User Guide (WHC-SD-SEC-CSUD-003. Rev.0)

\subsubsection{DEL_KeX}

This key will invoke a "delete" process outlined below.

1. A safety check prompt is then displayed is case of an errant keystroke.

YES

Proceed with Delete
NO

Cancel Delete Process

2. A "no" answer will display the following message: "Delete canceled...Press ENTER Key." The delete process is canceled and returns the user to the Edit screen.

3. A "yes" answer will take one of the two branches:

a. If the question is not a tultiple record type. the following menu is displayed at the top of screen:

Select Ffeld : Delete this field data only

All Ftelds : Delete ALL data fields on this record

ESC : Cancel delete process

Select Fjeld - This selection will delete just the contents of the data field that the cursor is on and the message "Field Deleted..." 1s displayed. The user is then returned to the Edit screen with the current record.

Al) Fields - This selection will delete the contents of al? the data fields. thereby leaving a blank record. A message "All Fjelds Deleted..." is then displayed. The user is returned to the Edit. screen displaying the current record.

(If this selection is made while editing Questions $1,2,3,5$, 6.7 or 8 . a message "All Fje]ds Dejetion Not Allowed in - Master Table..." is displayed and the user is returned to the Edit. screen with the current record displayed.)

- $\underline{\underline{E S C}}$

- Returns the user to the Edit screen displaying the current record.

b. If the question is a multiple record type, the following menu is displayed at the top of the screen:

Select : Delete only current sequential record

Al1 : Delete ALL current sequential records with this SSN

ESC : Cancel delete process

Is $=21$ 
QSP Version 4.0 User Guide (WHC-SD-SEC-CSUD-003, Rev.0)

Select - This selection will delete just the current record that was djsplayed when the DEL key was pressed. A "Record deleted" message witl be displayed and the program will return to display the previous sequential record (current record - 1 ). If that record has a different SSN than the one deleted. the progran will return the user to the Pre-Edit screen.

Al1 - This selection will delete all records with matching “" SSN. The number of records found and deieted will be displayed. The program returns the user to the PreEdit screen.

ESC - Returns the user to the Pre-Edit screen.

\subsubsection{F9 Key}

This key allows the user to view and edit the next: record in ascerding order for that SSN (current record +1 ). This is only useful with the multiple record questions e.g fig.f10.etc.

\section{2 .6 F10 Key}

This key allows the user to view and edit the previous sequential record for that SSN (current record - 1). This key is only usefu? with the multiple record questions a.g $\$ 9$, 10 .etc.

\subsubsection{F3 Key}

This key allows the user to switch from the previous enployment. table back to the most recent enloloynent perfod record. This key is only active with the multiple table question ti11.

\subsection{8 $\mathrm{F} 4 \mathrm{Ker}$}

This key allows the user to switch from the most recent employment period recard back to the previous employment table. This key is onfy active with the multiple table question \#il.

\section{2 .9 F $\mathrm{Key}$}

This key allows the user to invoke the Date Gap Check utility for any rultiple record questions with date ranges. but it is most applicable to Questions $\# 9$ (Residences) and HII (Eraploynant) which should not have date gaps. See Section 8.3 in Utitities for complete explanation. 
QSP Version 4.0 User Guide (WHC-SD-SEC-CSUD-003, Rev.0)

\subsubsection{ESC KeV}

This key does not save the current record inage. It will return the user to the Pre-Edit screen. It day be pressed at any time.

\subsubsection{OTHER EDITING KEYS}

CTRL-BACKSPACE - "Turbo Backspace" erases contents of the entíre . field.

CTL-F or ALT-F5 - This key witl enable the user to make changes within a field. With the cursor on the fteld. press the CTL $F$ key. By doing so the cursor will then be highlighted and by using the arrow keys the user can move freely within the field to get to the point of the error. By placing the cursor just right of the error and using the Backspace key. the user can remove any characters necessary and type in the correction. The BEL key may not be used for field and/or record deletion purposes. When the change has been made, press the Return key to exit out of Field Edit mode.

\subsection{MESSAGES FROM EDIT PROGRAM}

1. "SSN not found for Question $x x$

Do you wish to insert data for this question? (Y/N)"

CAUSE: No record was found after searching the appropriate data table with the entered SSN for a particular question number.

USER ACTION REQ'0: A "yes" answer will put the user into an insert mode for just that question. The program will Toop back to the Pre-Edit screen upon Teaving the insert mode. A "no" answer will cause the program to return to the Pre-Edit screen.

2. "No remaining records with this SSN..."

CAISE: The resultant message when no records matching the entered

SSE are found with either a F9 or F10 keypress.

USER ACTION REQ' D: None. Message is informational. 
QSP Version 4.0 User Guide (WHC-SD-SEC-CSUD-003, Rev.0)

3. "This Social Security Number is not present in Master Table (QST_1.8)"

CAUSE: The entered SSN was not found in the OSP Master table (QST 1-8) when the verify process was done. Only SSW's matching existing SSN's in the QSP Master table are allowed.

USER ACTION REQ'D: None. Program will automatically loop back to allow user to re-enter SSN or exit.

4. "Not one of the possible values for this field"

CAUSE: A number not matching the valid question numbers was entered. USER ACTION REQ'D: None. Progran will autonatically loop back to . allow user to re-enter question number.

5. "Duplicate Record exists... Check record sequence number"

CAUSE: An existing record was found matching the entered SSN. question number, and sequence number.

USER ACTION REO'D: Re-enter sequence number.

6. "Sequential number not allowed...Max Sequential recorods reached"

CAUSE: A sequence mimber equal to or greater than the maximum number allowed for a particular question was entered.

USER ACTION REQ' D: Re-enter sequence number.

7. "Inserting not al iowed in a non-repeating data table..."

CAUSE: INS key was pressed while editing a question that is not a multiple record question.

USER ACTION REQ'D: Press ENTER Key.

8. "This QSP is marked as completed \& archived. . Cancel..."

CALSE: When the entered SSM was being validated, the Date Archived field was non-biank indicating a completed/archived QSP.

USER ACTION REQ'D: 1 . Press any key. The program will contínue on.

Hote: This OSP may be recalled from the. Archive tables (see Sec 6.3) if tt has indeed been archived. Otherwise, the user may uninark the QSP by following Sec. 6.2 . 
QSP Version 4.0 User Guide (WHC-SD-SEC-CSUD-003. Rev.0)

9. "Delete Process Canceled..."

CAUSE: NO was selected at Delete Menu.

USER ACTION REO' 0: Press Enter key. Program will return to original edit screen.

10. "Insert Canceled..."

CAUSE: NO was selected at Insert Menu.

USER ACTION REQ'D: Press Enter key. Progran will return to original edit screen.

\footnotetext{
1,
} 
QSP Version 4.0 User Guide (hHC-SD-SEC-CSLO-003, Rev.0)

\subsection{PRINTING PROCEDURES}

\section{. 5.1 PRINT OSP FORM MEMU}

Upon selecting the PRINT QSP FORM at the Main Menu, the following screen will be displayed:

Enter SSN to be printed: (Blank SSN witl activat Name Search Process)

$\begin{array}{lll}\text { Page 1 }>\text { F1 } . & \text { Page 6 }>\text { F6 } & \text { A11 Pgs > Shft F1 } \\ \text { Page 2 > F2 } & \text { Page 7 }>\text { F7 } & \text { Extra Pgs (CPX) > Shft F2 } \\ \text { Page 3 }>\text { F3 } & \text { Page 8 > F8 } & \text { SFB6A PG A > Shft F3 } \\ \text { Page 4 }>\text { F4 } & \text { Page 9 > F9 } & \text { SF86A PG B > Shft F4 } \\ \text { Page 5 }>\text { F5 } & \begin{array}{l}\text { Page 10 }>\text { F10 } \\ \text { Page 11 }>\text { Alt F10 }\end{array} & \begin{array}{l}\text { Enter new SSN }>\text { Enter } \\ \text { Quit Menu > ESC }\end{array}\end{array}$

1. Fill-in the SSN and press the Enter key. If left.blank, the program will invoke the Name Search Process.

2. The program then verifies the entered SSN against the QSP Master file. If entered SSN is marked as completed. it will be assumed it has been archived and display "Archive" in the upper right hard corner of the Print Menu as which data table the QSP is being printed from.

3. If the entered SSN is still active, the word "Active" will be displayed in the upper right hand corner of the Print Menu screen. This reveals the set of data tables the QSP is being printed from.

4. If the entered SSN is valid, the user may then press the desired function key. These keys should be pressed one at a time. Once a Function key is pressed. the displayed equivalent is highlighted e.g. if the user presses F4, the characters "F4" change color to signify that a selection has been made.

NOTE: '1. If $F 2$ or $F 4$ is pressed, a check is made to see if there are enough records to print the continuation page A or B. If there are, the "Shft F3" and "Shft F4" will begin flashing on the screen. signailing the user that those pages are available to print. 
QSP Version 4.0 User Guide (WHC-SD-SEC-CSND.003, Rev.0)

NOTE: 2. Be careful pressing the various function keys. The keys can be sensitive. Holding down the function key will cause a number of keystroke signals to be sent to the program which will interpret each signal as a keystroke thereby causing it to print a page for each keystroke.

NOTE: 3 . The Shft-FI key will print pages 1-11 plus continuation pages which contain data automatically. This can tie up a printer for a while. In an effort to save paper. when executing a Shft-F1 print-out. the program will no longer print $\mathrm{CPX}$ continuation pages which do not contain data records.

NOTE: 4. The address and city of a person who can verify applicant's residence will print with the address data "stacked" above the city data.

NOTE: 5 . The nornumbered question at the bottom of page 6 which requests the numbers of any questions which have been continued on the CPX continuation sheet is entered only for the purpose of printing: $\mathfrak{i} \mathrm{e}_{\mathrm{i}}$ it is not stored in any QSP data table. Therefore. it witi be necessary to enter it each time the user accesses and then prints the SSA.

5. If the entered SSN is not valid. a message indicating such is displayed (see below), and the user may re-enter the SSN.

6. The user may stay in this menu and print as many pages as are needed. If multiple SSN's are to be printed, the user may press the Enter key after each SSN prints to completion: this will blank out the SSN and permit the user to enter a new SSN.

7. To leave the menu. press Esc.

\subsection{MESSAGES FROM PRIMT MENU}

1. "This Socjal Securjty Mumber is not present in the data files Press any key"

CAUSE: The entered SSN was not found in the QSP Master table (QST 1-8) when the verify process was done. OnTy SSN'S matching existing SSN's in the QSP Master table are allowed.

USER ACTION REQ'D; None. Program will automatically loop back to allow user to re-enter SSN or exit. 
QSP Version 4.0 User Guide (WHC-SD-SEC-CSUD-003, Rev.0)

2. "INVALID CHOICE... Try again"

CAUSE: A function key other than those valid was pressed.

USER ACTION REQ'D: None. Program will automatically loop back to . allow user to re-key selection.

3. "SSN Not Found in Master File... Insufficient data to produce Page 1... Press any Key*

CALSE: The entered SSN was not found in the Master file (OST_1-8) when F1 was pressed.

USER ACTION REO'D: None. The program will loop back for user to make another selection.

4. "Data table is empty..."

"Insufficient data to produce Page 1... Press any kej"

CAUSE: No data was found for the data table defined for Page 1 data (QST_1-8).

USER ACTION REQ'D: Mone. The program wiIT Toop back for user to make another selection.

5. "No Address records found for entered SSN... Checking now for School records..."

CALSE: The entered SSN was not found in the table containing residence history data (QST_9). It assumes that a person has to have at least 1 address. if not. don't print any of Page 2 until there is.

USER ACTION REQ'D: None. The program will automatically loop back to menu for user to make another selection.

6. "Address table is empty..." "Checking for School data to produce Page 2...Press any key"

CAUSE: Na data was not found in the table containing residence history data (QST_9).

USER ACTION REQ'D: None. The program will automatically loop back to . menu for user to make another selection. 
QSP Version 4:0 User Guide (WHC-SD-SEC-CSUD-003, Rev.0)

7. "School data table is empty...

"Press any key"

CAUSE: No data was found in the table defined for school history data (QST_10).

USER ACTION REQ'D: None. The program will autamatically loop back to a] low the user to make another selection.

8. "No Employment Histary records found for entered SSN..."

-Insufficient data to produce Page 3. . Press any key"

"No Employment History records found for entered SSN..."

"checking reference data table for Page 4..Press any key"

CAUSE: The entered SSN was not found in the table containing work history data (QST_11).

USER ACTION REQ'D: None. The program will atumatically " Toop back to allow the user to make another selection.

9. "Employment data table is empty..."

"Insufficient data to produce Page 3...Press any key"

CAUSE: Na data was found in the table defined for Eisployinent history data (QST_11).

USER ACTION REQ'D: None. The program will automatically loop back to allow the user to make another selection. .

10. "Reference data table is empty..."

"Press any key"

CAUSE: No data was found in the table defined for References data (QST_12).

USER ACTION REQ ${ }^{\circ} \mathrm{D}$ : None. The program will automatjically loop back to allow the user to make another selection.

11. "Marital Status data table is empty..."

"Checking rest of data tables for Page 5...Press any key*

CAUSE: No data was found in the table defined for Marital Status data (OST_13).

USER ACTION REO'D: None. The program will automatically loop back to allow the user to make another selection. 
QSP Version 4.0 User Guide (WHC-SD-SEC-CSUD-003, Rev.0)

12. "Relatives data table is empty..."

- CAUSE: No data was found in the table defined for Relatives data (QST_14).

USER ACTION REQ'D: None. The progran wil automatically loop back to allow the user to rake another selection.

13. "Citizenship of Relatives data table is empty..."

"Checking rest of data tables for Page 6... Press any key"

CAUSE: No data was found in the table defined for Citizenship of Relatives data (QST_15).

USER ACTION REQ'D: Hone. The program will automatically loop back to allow the user to make another selection.

14. "Military History data table is empty..."

CAUSE: No data was found in the table defined for Military History data (OST_16).

USER ACTION REQ'D: None. The program will automatically loop back to allow the user to nake another selection.

15. "Foreign Activities data table is empty..."

"Checking rest of data tables for $\rho_{\text {age }} 6 .$. . Press any key"

CAUSE: No data was found in the table defined for Foreign Activities data (QST_17).

USER ACTION REQ'O: None. The program will automatically loop back to allow the user to make another selection.

16. "Visited Foreign Countries data table is enpty..."

"Press any key"

CAUSE: No data was found in the table defined for Foreign countries have visited (OST_18).

USER ACTION REQ'O: None. The progras will autonatically loop back to allow the user to make another selection. 
QSP Version 4.0 User Guide (WHC-SD-SEC-CSUD-003, Rev.0)

17. "ATl Page 6 data tables were empty..."

"Insufficient data to produce page 6...Press any key"

CAUSE: No data was found in any of the tables defined for Page 5 data.

USER ACTION REQ'D: None. The program will automatically loop back to allow the user to make another selection.

18. "Military Recorcs data table is empty..."

"Chiecking rest of data tables for Page 7...Press any key"

CAUSE: No data was found in the tabie defined for Military Records (QST_19).

USER ACTION REQ'D: None. The program will automatica]7y loop back to allow the user to make another selection.

19. "Selective Service data table is empty..."

"Checking rest of data tables for Page 7...Press any key"

CAUSE: No data was found in the data table defined for Selective Service data (QST_20).

USER ACTION REQ'O: None. The program wiln automatically loop back to a]low the user to make another selection.

20. "Medical Record data table is empty..."

"Checking rest of data tables for Page 7...Press any key"

CALSE: No data was found in the data table defined for Medical Record data (QST_21).

USER ACTION REQ'D: None. The program will automatically loop back to allow the user to make another selection.

21. "Employment Record data table is empty..."

"Checking rest of data tables for Page 7...Press any key"

CAUSE: No data was found in the data table defined for Employment Record data (QST_22).

USER ACTION REQ'D: None. The program will automatically loop back to allow the user to make another selection. 
GSP Version 4.0 User Guide (WHC-SD-SEC-CSUD-003, Rev.0)

22." "Police Record data table is empty..."

"Press any key"

CAUSE: No data was found in the data table defined for Police Record data (QST_23).

USER ACTION REQ'D: None. The progrant will automatically loop back to allow the user to slake another selection.

23. "A11 Page 7 data tables were empty..."

"Insufficient data to produce Page 7...Press any key"

CAISE: Mo data was found in any of the tab?es defined for Page 7 data.

USER.ACTION REQ'D: None. The program will automatically loop back to allow the user to make another selection. ...

24. "Extra Continuation Page data table is empty..."

"Insufficieient data to produce Cont Page... Press any key"

CAUSE: No records were found in the "Extra Pages" data table.

USER ACTION REQ'D: None. The program will automatically loop back to allow the user to make another selection.

25. "Illegal Drug \& Alcohol data table is empty..." "Checking rest of data tables for Page B... Press any key"

CALSE: No data was found in the data table defined for Drug and Alcohol record data (QST_24).

USER ACTION REQ' 0 : None. The program will automatically loop back to allow the user to make another selection.

26. "Use of Alcohol data table is empty..."

- "Checking rest of data tables for Page 8...Press any key"

CAUSE: No data was found in the data table defined for Use of Alcohol record data (QST_25).

USER ACTION REQ'D: None. The program will automatically loop back to allow the user to make another selection. 
QSP Version 4.0 User Gujde (WHIC-SD-SEC-CSUD-003, Rev.0)

27. "Investígations Record data table is empty..."

"Checking rest of data tables for Page 8...Press any key"

CAISE: No data was found in the data table defined for Investigations Record data (QST_26).

USER ACTION REQ'D: None. The program will automatically loop back to allow the user to make another selection.

28. "Frnancial Record data table is empty..."

"Press any key"

CAUSE: No data was found in the data table defined for Financia? Record data (QST_27).

USER ACTION REQ'D: None. The program will automatica]ly loop back to allow the user to make another selection.

29. "Al1 Page 8 data tables were enpty..."

"Insufficient data to produce Page 8...Press any key"

CALSE: No data was found in any of the tables defined for Page 8 data.

USER ACTION REQ'D: None. The program will automatically loop back to allow the user to make another selection.

30. "Finarcial Delinquencies Record data table is empty..."

"Checking rest of data tables for Page 9... Press any key"

CAUSE: No data was found in the data table defined for Financial Record data (QST_28).

USER ACTION REQ'D: None. The program with automatically loop back to allow the user to make another selection.

.31. "Public Record Civil Court Action data table is empty...". "Checking rest of data tables for Page 9...Press any key"

CALSE: No data was found in the data table defined for Public Record Civil Court Action data (QST_29).

USER ACTION REQ'D: None. The program will autonatically loop back to allow the user to make another selection. 
QSP Version 4.0 User Gutde (WHC-SD-SEC-CSUD-003. Rev.0)

32. "Association Record data table is empty..."

"Press any key"

CAUSE: No data was found in the data table defined for Associations Record data (QST_30).

USER ACTION REQ'D: None. The program will automatically loop back to allow the user to make another selection.

33. "Page 9 Continuation Space data table is empty..."

CAUSE: No data was found in the data table defined for the Page 9 Continuation Space (PG9_CONT).

USER ACTION REQ'D: None. The program will automatically loop back to allow the user to make another selection.

34. "All Page 9 data tables were empty..."

"Insufficient data to produce Page 9...Press any key"

CAUSE: No data was found in any of the tables defined for Page 9 data.

USER ACTION REQ'0: None. The program with automatically loop back to allow the user to make another selection.

35. "Data table is empty..."

"Insufficient data to produce Page 10... Press any key"

CAUSE: No data was found in the data tables used for producing Page 10.

USER ACTION REQ'O: None. The program will automatically loop back to a Tlow the user to make another selection.

36. "No Name record was found with entered SSN..."

"Insufficient data to produce Page 10... Press any key"

CAUSE: No record was found in OSP Master File for use on Page 10.

USER ACTION REQ'D: None. The program will automatically loop back to allow the user to make another selection. 
QSP Version 4.0 User Gutide (hHIC-SO-SEC-CSUD-003, ReV.0)

37. "Data table is empty..."

"Insufficient data to produce' Page 11...Press any key"

CAUSE: No data was found in the data tables used for producing Page 11 .

USER ACTION REQ'D: None: The program wit a automatically loop back to al low the user to make another selection.

38. "No Name record was found with entered SSN..."

"Insufficient data to produce Page 11...Press any key"

CAUSE: No record was found in QSP Master File for use on Page 10.

USER ACTION REQ'D: None. The program witl automatically loop back to allow the user to make another selection.

39. "Data table is empty..."

"Insuffici ent data to produce Page A. . . Press any key"

CAUSE: Mo data was found in the data table used for producing Page $A$ of the SF86A Continuation Sheet (OST_3-8).

USER ACTION REQ'D: None. The program will automatically loop back to allow the user to make another selection.

40. "Address data table is empty..."

"Checking for overflow School data records... Press any key"

CAUSE: No data was found in the data table defined for Question 9 (QST_9).

USER ACTION REQ'D: None. The program will automatically loop back to al low the user to make another selection.

41. "No ȘFa6A Continuation Page A produced..."

CAUSE: No more extra records were found for Questions 9 and 10. .

USER ACTION REQ'D: None. The program will automatically loop back to allow the user to make another selection. 
QSP Version 4.0 User Guide (HHC-SD-SEC-CSUD-003. Rev.0)

42. "Employment data table is empty..."

"Insufficient data to produce Page B...Press any key"

CAUSE: No extra records were found for Question 11.

USER ACTION REQ'D: Nome. The program will automatically loop back to allow the user to make another selection.

43. "Wo SF86A Continuation Page B produced..."

"lack of overflow data..."

CAUSE: No more extra records were found for Question 11.

USER ACTION REQ'D: None. The program will automaticaliy loop back to allow the user to make another selection.

44. "No forn will be printed as no data was entered for this \$SN..."

CAUSE: A record was created for the SSN, but no data has been entered.

USER ACTION REQ'D: None. The program will automatically loop back to allow the user to make another selection.

45. "No extra continuation records found with entered SSN..."

"Insufficient data to produce form... Press any key"

CAUSE: The table has records, but none matching the SSN.

USER ACTION REQ'D: None. The program will automatically loop back to allow the user to make another selection. 
QSP Version 4.0 User Guide (UAC-SO-SEC-CSUD-003, Rev.0)

\subsection{ARCHIVE MOONLE}

\subsection{CHOICES}

Upon selecting the ARCHIVE MODULE at the Main Menu. the following menu is displayed:

Mark Completed QSPS Recall Archived QSPS Query Archived QSPS Quit

To select any of the choices, either highlight the choice and press Enter key or type in the first letter of the choice.

\subsection{MARK COMPLEIED OSPS}

This selection menu is an optional. It is not a required procedure for QSP version 4.0. . Therefore you may skip the following steps: 6.2.1. $6.2 .2,6.2 .3$.

This choice allows the user to mark a QSP as complete by filling in a Date Completed field. This date field is then used by the off-hours archive program to select it and archive it by placing it in the archive tables. It may also be used to unmark completed QSPS provided the archive program has not been rum. To cance? the marking process at any time. press Esc at any of the three prompts. The following is displayed:

MARK / UNMARK COMPLETED QSPS

SSN:

DATE COMPLETED:

CLERK'S INITIALS:

$>$ Fi1T-in SSN and Date Completed fields of completed QSP. To cancel marking process. Press ESC key.

$>$ Hitting Space Bar 3 times will fill-in w/Today's date if desired.

$>$ B1ank out Dațe Completed wil1 cancel archiving this QSP. 
QSP Version 4.0 User Guide (WHC-SD-SEC-CSUD-003. Rev.0)

\subsubsection{TO MARK COUPLETED OSPS:}

1. At the prompt. type the SSH of the completed OSP and press Enter key.

2. The program then verifies the entered SSH against the QSP Master File.

3. At the prompt, type the date QSP was completed and press Enter. key. (Shortcut: If today's date is to be used, pressing the Space bar 3 times will ff?

4. At the prompt. type your initials and press Enter key.

5. The program will automatically loop back to prompt for another SSA. To stop the marking process. press Esc key.

\section{2 .2 TO UNMARK_A.OSP:}

1. At the prompt, type the SSN of the completed QSP you wish to unmark and press Enter key.

2. The program then verifies the entered SSN against the QSP Master Fije.

3. Press any key if message is displayed.

4. Blank-out date field by pressing Backspace key.

(Shortcut: Press CTRL-Backspace keys once to biank out entire date field.)

5. Leave initials in field. Press Enter key.

6. QSP is now unmarked. To exit, press Esc key.

\subsubsection{MESSAGES FROM MARK/UNMARK PROCESS}

1. "SSN not found in Master Table... Recheck SSN or blank out to quit"

CALSE: Entered SSN was not found during validation process. USER ACTION REQ'D: Press any key to continue. Re-enter SSH or Esc key to quit. 
QSP Version 4.0 User Guide (WHC-SD-SEC-CSUD-003, Rev.0)

\subsection{RECALL ARCHIVED OSPS}

This choice allows the user to bring back a previousiy archived QSP and make it active again by moving it from the archive data tables back to the active data tables. The user has the option to lookup a person by name and then select the person frofl the screen. The following is the recall screen:

RECALL ARCHIVED QSP

SSN:

$>$ Fi11-in SSN or Blank SSN activates Name Search.

$>$ To cancel \& exit, Press ESC key.

\subsubsection{ID RECALL BY SSN:}

1. Enter SSN of the desired archived QSP and press Enter key. Blank SSN activates the Name Search Utility.

DO NOT INTERRUPT PROCESS ONCE IT HAS STARTED!!!

2. The progiram wil? then verify the entered SSN against the archive Master File. If not vaifo, a message indicating such will be displayed with a prompt to continue. If valid. the recall process wi II begin and a "Recall in Progress" message is displayed. After the archive records are copied to active data tables. the program deletes them from the archive tables so there will be no archive copy. Note: The Recall process does NOT copy over archived A-P data items. These must be keyed in new by the QSP clerk.

3. After the recall process reaches table 25 of 25 , the program wi if return to the Archive Menit Screen and the QSP is available for editing, printing, etc. 
QSP Version 4.0 User Guide (WHA-SD-SEC-CSUD-003, Rev.0)

\subsubsection{MESSAGES FROM RECALL PROCESS}

1. "Entered SSN not found in Archive Master Tabje...Press any key" CAUSE: Entered SSN was not found during validation process. USER ACTION REO'D: Press any key to continue. Program will return to Archive Menu Screen.

2. "No more records that match entered value(s)..."

CAUSE: No other records matching the entered name were found after the F2 key was pressed.

USER ACTION REQ'D: Press any key. Program will return to Archive Merus Screen.

3. "No match found matching entered values... Re-enter "̈alue(s)" CAUSE: No record was found matching the entered value.

USER ACTION REQ'D: Press any key. Program will loop back to enter new Fjrst and Last name.

4. "Recal1 in Progress. . . DO NOT INTERRUPT!"

CAUSE: All entered values have passed validation process and recal1 process has begun.

USER ACTION REQ'D: None. Informational message only. 
QSP Version 4.0 User Guide (WHC-SD-SEC-CSUD-003. Rev.0)

\subsection{QULERY ARCHIVED OSPS}

This choice allows the user to lookup or "query" information from QSPS that have been previousiy archived. The query process is done by question number much Tike the Edit mode on active QSPS. However. the user tias the option of querying by name if the SSN is not readily known. The Recall screen as shown in 6.3 above is used by the query program.

QUERY ARCHIVED QSP

SSN:

$>$ Fill-in SSN or Blank SSN activates Name Search.

$>$ To cancel \& exit. Press ESC key.

\subsubsection{TO QJERY BY SSN:}

1. At the prompt. type the SSN and press Enter key. Blank SSN wi 11 activate the Name Search Utility.

2. The progran will then verify the entered SSN against the archive Master File. If not valid, a message indicating such witl be displayed with a prompt to continue.

3. If valid, type question number and press Enter key.

4. The program will verify the question number against a lookup table that contains all valid question numbers.

5. If entered question number is invalid. a message indicating such is displayed and the user will have to re-enter it.

6. If question number is valid and a data record exists. the record is displayed.

7. If no data exists for entered question. a message jndjcating such is displayed and the user with have to press a key for the progrant to return to the Archive Menu Screen. 
QSP Version 4.0 User Guide (WHC-SD-SEC-CSUD-003, Rev.0)

8. Once a record is displayed, four (4) key choices appear at the top of the screen: F2 or Esc will return user back to Archive Menu Screen, Fg key will display the next sequential record if the question is a multi-record type of question i.e. \#9. \#10. \#I1. Conversely, the F10 key will display the previous sequential record.

9. Press F2 or Esc to end query and return back to the Archive

- Menu Screen.

\subsubsection{MESSAGES FROM ARCHIVE QUERY PROCESS}

1. "SSN not found for question $x x, . . "$

CAUSE: No data was found for the particular question number when program searched using entered SSN.

USER ACTION REQ'D: Press any key to continue. Program will loop to allow user to re-enter Question number. 
QSP Version 4.0 User Guide (WHC-SD-SEC-CSUD-003, Rev.0)

\subsection{UTILITIES}

\subsection{CHOICES}

Upon selecting UTILITIES at the Main Menu. the following menu is displayed:

LOCATE BY NAME DATE GAP CHECK BLANK FIELD CHECK MODIFY SSN
OELEETE QSP RECS DELETE PART 2 ONLY LIST ALL QSPS
PRINT BLANK QSP PACKAGE EDIT A-P DEFAULT VALUES QUIT

To select one. either highlight the choice and press the Enter key or type the first letter of the choice.

\subsection{LOCATE BY NAME}

This choice allows the user to search through the active QSP Master File to determine a person's SSN by entering the person's First and Last name or just part of the Last name.

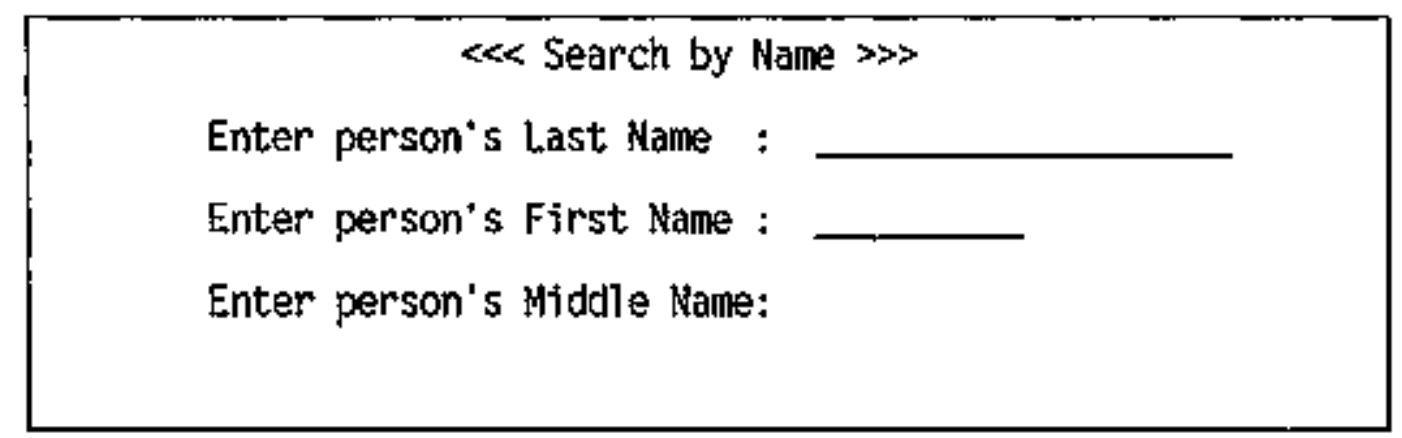

1. At the prompts, type the person's Last Name, First Name. and Middle Name if you know them. and press the Enter key. If you are not sure of the person's name, it is possible to use a "wild card" to perform a search by entering as much of the Last Name and First Name as you can, followed by two periods. For example. if the person's Last name is FISCHER and you are not sure whether it is FISCHER or FISHER, you could enter "FIS.." and press the Enter key. To cancel the search. press Esc key at either prompt.

2. If a match is found, the first matching record is displayed.

3. If no match is found, a message indicating such is displayed. and the user will have to press a key to return to the utilities Menu Screen. 
QSP Version 4.0 User Gujde (WHC-SD-SEC-CSLD-003, Rev.0)

4. Once a record is displayed, three (3) Key choices appear at the top of the screen. The F2 key will search for the next record matching the entered values. If more matches are found, they are displayed one at a time. The Esc key will return the user back to the Utilities Menu Screen.

5. If the correct match is displayed on the screen. select the displayed SSA by pressing the F5 key. The SSH wi î be captured and validated, and the record will be returned to the operationfrom which the name search was invoked.

6. Press Esc key to return to the Utilities Menu Screen.

\subsubsection{MESSAGES FROM LOCATE BY MAME PROCESS}

1. "No more records that match entered values..."

CAISE; No other records matching the entered name were found after the F2 key was pressed.

USER ACTIOH REQ'D: Press any key. Program wit? return to Uti lities Menu Screen.

2. "No match found matching entered vaiues... Re-enter value(s)"

CAUSE: No record was found matching the entereo value.

USER ACTION REQ'D: Press any key. Program will loop back to enter new value.

3. "All key "ffelds are blank... Last name is the minimun to be used..."

CAUSE: Hothing entered in any of the fields to be used for the search.

USER ACIION REQ' D: None. The program will automatically loop back so that the user can enter search key value. 
QSP Version 4.0 User Gúde (WHC-SD-SEC-CSUD-003,-Rev.0)

\subsection{DATE GAP CHECK}

This utility can be either selected from the Utilities Menu Screen or invoked by pressing the F5 key in Edit Mode (see 5.2.9 on page 24).

\section{DATE GAP CHECK}

Enter -Social Security Number.:

Enter QSP Question Number....:

1. To cance1, press ESC key.

2. Blank SSH will activate Name Search.

3. For cont. pages, Question no. $C P 1 \Rightarrow P$ g. 9. CPX $=E x t r a$ Pages

1. At the first prompt. enter SSN (a blank SSN will bring up the Search by Name screen).

2. At the second prompt, enter the question number for which you would like to check the date ranges, and press the Enter key.

3. The program will search for records with a date gap and return a message at the top of the screen. It will also write the message to a report file.

4. Press any key to continue the search. When the search is complete, the user will be prompted to press the F10 key to view the Date Gap Report or [Esc] to cancel.

5. When viewing the oate Gap Report the user can print the report by pressing ' $P$ '. view a HELL screen by pressing the F1 key, or cancel by pressing [Esc].

6. NOTE: This utility is able to detect and ignore a special character used to designate an approximate date.

\subsection{1 프SSAGES EROM DATE GAP CHECK}

1. "Oate Gap checking is not allowed on this question..." CAUSE: A non-multiple record question was selected.

USER ACT ION REQ 0 : None Program will automatically loop back to allow the user to make another selection.

2. "Date Gap checking is not done on this portion..." CALISE: A non-multiple record question was sejected. USER ACTION REQ'D: None. Program wîll automatically loop back to ailow the user to make another selection. 
QSP Version 4.0 User Gutde (WHC-SD-SEC-CSUD-003, Rev.0)

\subsection{BLANK DATA FIELD CHECK}

This utility can be selected from the Utilities Menu Screen.
B L A'N K
DAT A F I E L D
U T I L I T Y

Enter Social Security Mumber::

Enter 1 to check 1 question or

A to check All questions:

1. To cancel, press ESC key.

2. Blank SSH will activate Name Search.

3. For cont. pages, Question no. CPI=\$g. 9, ' $C P X=E x$ tra Păges

1. At the first prompt, enter SSN (a blank SSN will bring up the Search by Name screen).

2. At the second prompt. enter ' 1 ' if only one question is to checked or ' $A$ ' if ali questions are to be checked, and press the Enter key.

3. If the user entered ' 1 ', a second screen will be brought up which will prospt for the question number to be checked:
B L A N K
D A T A
F IEL D
U T I L I T Y

Enter QSP Question Number:

1. To cancel, priess ESC key.

2. Blank SSN wij] activate Name Search.

3. For cont. pages, Question no. CP1×Pg. 9, CPX = Extra Pages

Enter the question number to be checked and press Enter.

4. The progras wi1l search for data fields with nothing entered in them and write them to a report file. When the search is - complete, the user will be prompted to press the F10 key to view the Blank Field Report or [Esc.] to cancel. 
QSP Version 4.0 User Guide (WHC-SD-SEC-CSUD-003, Rev,0)

5. When viewing the B?ank Fie?d Report the user can print the report by pressing ' $\mathrm{P}$ '. view a HELP screen by pressing the $\mathrm{F} 1$ key, or cancell by pressing [Esc].

\subsubsection{MESSAGES_ERON BLAN DATA FIELD CHECK}

1. "Ho biank fields detected..."

CAUSE: The prograti found no blank data fields for the question(s) searched.

USER ACTION REQ'D: None. Program will autosiatically loop back to alTow the user to make another selection.

\subsection{MODIFY SSN}

This choice allows the user to change records that contain an incorrect SSN. The progran will autonatically go through all the data tables displaying a running total of the number of records changed and the table being changed. Pressing Esc key at either prompt cancels the modification process. Use caution since SSN is THE key field in the system.

$$
\begin{aligned}
& \text { S SN CHANGE UTILITY } \\
& \text { Enter Wrong SSN: } \\
& \text { Enter Correct SSN: }
\end{aligned}
$$

1. At the prompt. type the WRONG SSN and press the Enter key.

2. At the prompt. type the CORRECT SSN and press the Enter key.

3. The program will now go through all the data tables and change the affected records. DO NOT INTERRUPT THIS PROCESS!!!

4. When done, the program will display a message and the user must press a key to return to the Utilities Menu Screen.

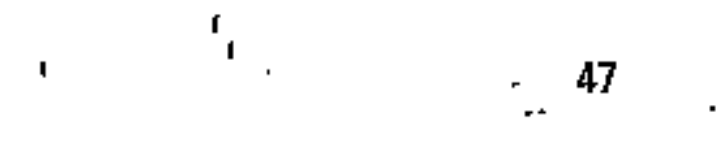


QSP Version 4.0 User Guide (WHC-SD-SEC-CSLD-003, Rev.0)

\subsubsection{MESSAGES FROK MODIFY SSH_PROCESS}

1. "This QSP is marked as completed \& archịved...Cance $7^{*}$

CAUSE: When the entered SSN was being validated, the Date Archived field was non-blank indicating a completed /archived QSP.

USER ACTION REQ'D: Press any key. The progran will continue on:

2. "Records exist containing new correct SSN...Use Edit Mode..."

CAUSE: When a check was made to see if any records exists with the new entered SSH. some were found.

USER ACTION REQ'D: Press any key. Program will return to Utifities Menu Screen.

3. "Erroneous SSN not found in Master table...Canceling process..."

CAUSE: The SSN that was entered as the "Wrong" SSN was not found in the particuiar aSP data tabie. It indicates that no data was entered in that table.

USER ACTION REQ'D: None: Informational message only. Program will move on to the next table.

4. "A11 Done Changing SSNS in the QSP Tables $1+1 ! \ldots$...

CAUSE: All data tables have been searched and all affected records have been modified. Its all done basicaliy.

USER ACTION REQ'D: Press any key. Program will return to utilities Menu Screen.

i 
QSP Version 4.0 User Guide (WHC-SD-SEC-CSUD-003. Rev.0)

\subsection{DELETE OSP RECOROS}

This choice allows the user to delete a person's entire QSP from the system. Use Caution. Process cannot be reversed.
Q S P RECOR D
DE L. E T E
U T I L I T Y
Enter SSN of Person to DELETE from System:

1. At the prompt, type the person's SSN and press the Enter key. NOTE: The Name Search Utility will not be invoked if the SSN is left blank. The user must be absolutely positive about whose records are to be deleted.

2. A safety valve message appears with a Yes/No continuation prompt. A "Yes" answer will start the deletion process. A "No" answer with return the user back to the Utifities Menu Screen.

3. If " $Y "$ is entered, the program will now go through all the data tables and delete the affected records. DO NOT INTERRUPT THIS PROCESS!!!

4. When done, the program will display a message and the user must press a key to return to the utilities Menu Screen.

\subsubsection{MESSAGES FROM DELETE RECORDS PROCESS}

1. "This OSP is marked as completed \& archived...Cancel..."

CAUSE: When the entered SSN was being validated, the Date Archived field was non-blank indicating a completed /archived QSP.

USER ACTION REQ'D: 1 . Press any key. The program will continue on,

2. "All Done Deleting This Person From The QSP System..."

CAUSE: Program is finished deleting records. All tables have been searched.

USER ACTION REQ'D: Press any key. Program will return to Utiłtities Menu Screen. 
QSP Version 4.0 User Guide (WHC-SD-SEC-CSLD-003, ReV.0)

\subsection{DELETE QSP PART 2 ONLY}

This choice allows the user to delete just Part 2 of a person's QSP from the system. Use Caution. Process_cannot be reversed.

\section{QSP PART 2 DELETE UTILITY \\ Enter SSH of Person to DELETE from System:}

1. At the prompt, type the person's SSN and press the Enter key. NOTE: The Name Search utility will not be invoked if the SSN is left blank. The user must be absolutely positive about whose records are to be deleted.

2. A safety valve message appears with a Yes/No continuation prompt. A "Yes" answer will start the deletion process. A "No" answer will return the user back to the Utilities Menu Screen.

3. If " $Y$ " is entered, the program will start at Question 19 and go through all the remaining data tables and delete the affected records.

DO NOT INTERRUPT THIS PROCESS!!!

4. When cone, the program will display a message and the user must press a key to return to the Utilities Menu Screen.

\subsubsection{MESSAGES FROYLOELETE OSP_PART_2_OKLY}

1. "This QSP is marked as completed \& archived...Cancel"

CAUSE: when the entered SSN was being validated, the Date Archived field was non-blank indicating a completed larchived QSP.

USER ACTHON REQ'D: Press any key. The program with continue on.

Note: This QSP may be recalled from the Archive tables (see Sec 7.3) if it has indeed been archived. Otherwise, the user may unmark the QSP by following Sec. 7.2.

$$
\text { ', }
$$


QSP Version 4.0 User GuSde (WHC-SD-SEC-CSUD-003, Rev.0)

2. "This Social Security Ntmber is not found in liaster Table (QST_1-8)."

CAUSE: The entered SSN was not found in the QSP Master table (QST 1-8) when the verify process was done. Only SSN's matching existing SSN's in the QSP Master table are al rowed.

USER ACTION REQ'D; None. Program will automatically loop back to alfow user to re-enter SSN or exit.

3. "Continuation space on Page 9 and Extra continuation pages should be edited individually for possible Part 2 data... Press any key"

CAUSE: None.

USER ACTIOA REQ'0: None. This is an informational message. Prograln wijl loop back to allow user to perform any necessary editing.

\subsection{LISIALL_OSP'S}

This utility will create a formatted listing of all active and archived QSP's in the system. The report wi1l contain the SSN. the Last' narse. First name, and Middle initial of the applicant. See example in Appendix $\mathrm{H}$.

\subsection{PRINT BLANK OSP PACKAGE}

This choice automatically initiates the printing of a complete 13 page blank QSP Packet.

\subsection{EDII A-P. DEFAÜLI VALUES}

This option allows the user to edit the default values of the data fields that have been designated as a default field.

1. The program will list each default value field by its field name and its current default value setting. The user is given three choices: $Y=$ edit that value. $N=$ going to next default field. and $X=$ canceling edit and return to menu.

2. If the user edits the default value a prompt appears asking if the value is correct. A "yes" answer witl accept the new default value and go on to the next default field. A "no" answer allows the user to re-enter a new default field value.

3. The program will return to the Utilities Menu after' all the default fields have been displayed or when an " $X$ " is entered. 
QSP Version 4.0 User Guide (WHK-SD-SEC-CS1D-003, Rev.0) APPENDIX A

QUESTIONNAIRE FOR MATIONAL SECURITY POSITIONS (QNSP) BLANK FORNS

$\cdot 1$, 